\title{
Size, trend, and policy implications of the underground economy
}

\author{
Renzo Orsi $^{a}$, Davide Raggi ${ }^{\mathrm{a}, *}$, Francesco Turino $^{\mathrm{b}}$ \\ a Dipartimento di Scienze Economiche, Università di Bologna, Piazza Scaravilli 2, 40126 Bologna, Italy \\ b Departamento de Fundamentos del Anàlisis Económico, Universidad de Alicante, 03071 Alicante, Spain
}

\section{A R T I C L E I N F O}

\section{Article history:}

Received 3 October 2012

Received in revised form 31 October 2013

Available online 27 November 2013

\section{JEL classification:}

E26

E32

E62

H26

C11

Keywords:

DSGE

Underground economy

Tax evasion

Bayesian estimation

Italy

\begin{abstract}
A B S T R A C T
We study the underground economy within a dynamic and stochastic general equilibrium framework. Our model combines limited tax enforcement with an otherwise standard twosector neoclassical stochastic growth model. The Bayesian estimation of the model based on Italian data provides evidence in favor of an important underground sector in Italy, with a size that has increased steadily over the whole sample period. We show that this pattern is due to a steady increase in taxation. Fiscal policy experiments suggest that a moderate tax cut, along with a stronger effort in the monitoring process, causes a sizeable reduction in the size of the underground economy and provides a positive stimulus for the regular economy. Both of these effects jointly increase total fiscal revenues.
\end{abstract}

(c) 2013 Elsevier Inc. All rights reserved.

\section{Introduction}

The underground economy represents a major issue when studying an economic system because of its large impact on public finances and its distorting effects on production, as it creates unfair competition between firms. Furthermore, it may create additional social costs because the overall tax burden is shared between a smaller number of citizens, thus increasing economic inequality, and because of the lack of labor protection for the individuals who are working in the underground market.

Available empirical evidence shows that the underground economy is a significant issue for most countries, albeit to varying degrees. In fact, the underground economy is universally widespread; it is present in developing as well as in advanced economies. In particular, there exists evidence of a growing trend for irregular economies due to the combined effects of international competition and the high degree of fragmentation of working organizations (see e.g. Schneider et al., 2010). Furthermore, legal activities conducted underground in order to avoid taxation appear to be the fastest growing component of the underground economy, largely because of the way tax systems are structured.

Because of its latent nature, measuring the underground economy is difficult, and the discussion regarding the most appropriate methodology to use in order to quantify this phenomenon is still ongoing. In this paper we aim to measure the underground economy through a structural econometric approach, which exploits equilibrium conditions from an economic model to provide estimates for unobservable variables. We assume that unobserved data may be derived from a

\footnotetext{
* Corresponding author.

E-mail addresses: renzo.orsi@unibo.it (R. Orsi), davide.raggi@unibo.it (D. Raggi), fturino@ua.es (F. Turino).
} 
well-behaved theoretical model by using the so-called theory for measurement approach, as implemented in the seminal paper by Ingram et al. (1997). To this end, we build and estimate a dynamic stochastic general equilibrium (DSGE) model that explicitly accounts for concealed transactions. The inferential procedure that we use, which is based on the Markov chain Monte Carlo methods (MCMC), allows us to estimate the dynamics of the unobservable underground economy together with the parameters of the model. This approach departs radically from the traditional methodologies proposed in the literature to estimate the underground economy, and in our view offers two main advantages. First, because it is theory-based, we believe that the DSGE methodology provides a deeper understanding of the causes of the underground economy. Second, the estimated model makes it possible to assess the fiscal policy implications of the underground economy from a general equilibrium perspective.

The model we propose combines incomplete tax enforcement à la Allingham and Sadmo (1974) with an otherwise standard two-sector neoclassical stochastic growth model. In this environment, the underground economy emerges as a result of incentives for agents to conceal their transactions in order to avoid taxation. This structure is adapted from Busato and Chiarini (2004) who are among the first to include the underground economy in a DSGE model. ${ }^{1}$ Our model differs from theirs in three main aspects. First, we allow for labor adjustments along the intensive margin. This property is important in order to relax sign restrictions on the co-movements among variables that are implied by the Busato and Chiarini model. Second, we consider a richer set of exogenous shocks, which are necessary to take the model to the data. More specifically, in addition to fiscal and sector-specific technological shocks, we also consider labor supply and investment-specific shocks. These additional shocks have been shown to be important in explaining the variability of data at business-cycle frequencies (see e.g. Smets and Wouters, 2007; Justiniano et al., 2010). Third, our model features a deterministic growth rate driven by labor-augmenting technological progress. Because of this property, the data do not need to be detrended before estimation.

We estimate the model using Italian quarterly data for the interval from 1982:Q1 to 2006:Q4. Italy makes for an interesting case study because, according to the available evidence, the underground economy is proportionately larger than in other developed countries (see Schneider et al., 2010). Furthermore, the recent severe sovereign debt crisis in Italy requires policy makers to propose effective policies to fight against tax evasion. The results of the Bayesian estimation provide evidence in favor of a sizeable underground sector in Italy. According to our results, the size of the underground economy has steadily increased over the whole sample period, and this pattern can be explained primarily by the steady increase in taxation that has occurred in Italy since the nineteen-eighties. The estimated model is then used to assess the implications of alternative fiscal policies. We find that at the current tax rates, Italy is on the slippery side of the steady-state Laffer curve, and could improve its budgetary situation either by reducing taxes or intensifying tax enforcement efforts. However, the analysis of transitional dynamics reveals that the optimal strategy would entail a mix of the two policies as, according to our findings, this turns out to be the only fiscal adjustment which would improve welfare and permanently increase fiscal revenues at the same time.

This paper is organized as follows: Section 2 defines what is meant by the term underground economy and reviews the literature, emphasizing the methodologies that have been implemented to measure this phenomenon. The DSGE model is presented in Section 3, while the inferential methodologies and the description of the data are included in Section 4. The empirical results are provided in Section 5, and the policy implications are analyzed in Section 6. Finally, Section 7 concludes the paper.

\section{Current approaches in estimating the underground economy}

Information on underground economic activities, their magnitude and the way in which they occur are difficult to obtain since, by their nature, they cannot be monitored. Thus, quantifying the size of the underground economy must be based on estimation. Many attempts have been made to tackle this problem (see for instance Schneider, 2005 and Schneider and Enste, 2012, among others), although disagreements still exist regarding the definition of the term underground economy and the optimal approach for estimating its size.

The OECD addressed these questions almost a decade ago when it proposed definitions and harmonization procedures aimed at including the underground economy in the gross national product (OECD, 2002). The goal was to provide rules for the indirect measurement of the economic activities which are not included in the official statistics but which might constitute a significant part of a country's economy. Starting from the 1990s, the national statistical institutes of the OECD countries adopted an international definition established through the SNA93 and SEC95 accounting systems, which provides a yardstick for national accounting estimates and guarantees homogeneity in the statistical evaluation of GDP. To provide a definition that makes the concept of underground economy comparable and fairly uniform for European community member states, the European Union's statistical office (Eurostat) has provided details on how to account for the non-observed economy.

Specifically, the non-(directly-)observed economy is composed as follows:

- The underground economy, which regards legal production which is unofficial and unrecorded in order to avoid compliance with taxation, social security, labor and administrative legislation.

\footnotetext{
1 Another strand of literature focuses on models with heterogeneous agents along the line of Lucas (1978) (see e.g. Amaral and Quintin, 2006; Antunes and Cavalcanti, 2007; de Paula and Scheinkman, 2011). We depart from this literature by assuming that the economy is characterized by homogeneous agents.
} 
- The informal economy, which includes all legal activities carried out by individuals, small or home enterprises (part-time secondary work, moonlighting, baby-sitting and so on) and goods and services produced and consumed within the household. For these activities, it is very difficult, or even impossible, to rely on statistical observation and measurement, even if they are not directed toward tax evasion. Thus, they are not included in the underground economy, as defined above.

- The illegal economy, which includes all criminal economic activities such as trade in illegal drugs, prostitution, etc.

Throughout the paper, the term underground economy shall be used to refer to the production of legal commodities and services which is deliberately concealed from public authorities in order to avoid the payment of taxes or social security contributions. Our definition therefore does not include informal and criminal economic activity. In other words, according to our definition, illegal activities as they pertain to the underground economy are a function of the ways in which legal economic activities are conducted.

Procedures for estimating the underground economy distinguish between direct and indirect methods. Direct approaches are implemented essentially at a microeconomic level and are mainly based on surveys on households and businesses, or on evidence generated by the revenue services. Indirect methods infer the size of the underground economy by comparing macroeconomic indicators, for instance, by looking at differences between income produced and consumption, savings and investments, or alternatively by comparing electricity inputs with industrial output, or even by measuring the gap between actual currency demand with the demand for currency in the absence of taxation (Cagan, 1958; Tanzi, 1980, 1983; Gutmann, 1977).

A third way of estimating the underground economy is model-based, in which the underground economy is treated as a latent variable. In this respect, Frey and Weck-Hannemann (1984) and Giles (1999) propose a factor model known as Multiple Indicator Multiple Cause (MIMIC) in which the underground economy is linked to a set of indicators and causal variables by means of a system of linear equations. The size of the underground economy is evaluated by predicting the unobserved variable through standard regression techniques. MIMIC can thus be seen as a reduced form, or purely statistical model, in which no assumptions are made a priori regarding the relationship between the variables, and thus regarding the underlying economic structure.

In this paper, we propose a structural, model-based approach for the analysis of the phenomenon of the underground economy. In particular, we build and estimate a DSGE model, in which the underground economy is defined as a latent variable, that is the outcome of rational choices of economic agents. In this way, we link the underground sector to other economic variables, not just by defining a statistical mechanism as in the MIMIC approach, but through a dynamic system which preserves the structure of the model economy.

\section{Model}

We consider an economy which consists of a continuum of homogeneous goods that are indexed by $i \in[0,1]$, each produced by a perfectly competitive producer. Goods are sold by firms to a continuum of measure 1 of identical households for consumption and investment purposes and to the government, which collects taxes from households and firms in order to finance public spending. The economy is divided into two sectors, the official and the unofficial sector, and none of the transactions occurring in the latter are recorded by government authorities. Firms therefore use factors from underground markets to hide part of their production for tax evasion purposes. In each period of time, however, firms face a non-negligible probability of being inspected by the fiscal authorities, convicted of tax evasion and forced to pay taxes augmented by a penalty surcharge. Households might also avoid personal income tax by reallocating their labor services from the regular to the underground sector, and by supplying capital in the underground market. All of the interactions between firms, households and the government occur in a stochastic environment in which the short-run dynamics of the economy are driven by productivity, preferences, investment, and fiscal shocks.

\subsection{Firms}

Each firm $i$ uses regular labor, $h_{i, t}^{m}$, and regular capital, $k_{i, t}^{m}$, to produce regular output via a Cobb-Douglas production function

$$
y_{i, t}^{m}=A_{t}\left(\Gamma_{t} h_{i, t}^{m}\right)^{\alpha}\left(k_{i, t}^{m}\right)^{1-\alpha}
$$

where $\alpha \in(0,1), A_{t}$ is a purely transitory technological shock, while $\Gamma_{t}$ is the labor-augmenting technological progress, which follows a deterministic trend of the form $\Gamma_{t}=\gamma \Gamma_{t-1}$ with $\gamma>1$. Each unit of corporate income, defined as output produced net of labor costs, is taxed at the stochastic corporate tax rate, $\tau_{t}^{c}<1$. However, compliance is only partial, and firms can hide part of their production to evade taxes. To do so, firms may produce underground output by combining unofficial labor, $h_{i, t}^{u}$, with unofficial capital, $k_{i, t}^{u}$, via the following Cobb-Douglas technology:

$$
y_{i, t}^{u}=B_{t}\left(\Gamma_{t} h_{i, t}^{u}\right)^{\alpha_{u}}\left(k_{i, t}^{u}\right)^{1-\alpha_{u}}
$$

where $B_{t}$ is a purely transitory technological shock, and $\alpha_{u} \in(0,1]$. 
The assumption of sector-specific technological shocks incorporates potentially important inter-sectorial differences in labor productivity into the model. ${ }^{2}$ This property is consistent with available empirical evidence, which documents a clear association between level of education and participation in the irregular labor market (see e.g. Marcelli et al., 1999; Gallaway and Bernasek, 2002). The sector-specific shock $B_{t}$ can also be interpreted as capturing exogenous changes in the overall labor force which primarily affect irregular workers' productivity. For example, several empirical papers have documented that most workers hired under irregular work arrangements are immigrants (see e.g. Leonard, 1998). As noted by Busato and Chiarini (2004), it is reasonable to assume that these individuals have strong incentives to be highly productive to increase their chances of being hired as regular workers. An increase in legal immigration might therefore result in a temporary boost to the underground sector's productivity.

Following Busato and Chiarini (2004), we assume that goods produced in the underground sector are indistinguishable from regular goods, and that therefore, at equilibrium, their prices must be the same. ${ }^{3}$ Thus, without loss of generality, we will assume hereafter that the common price of the two goods is normalized to 1 at each point in time. The total final output produced by a firm $i$ at date $t$, namely $y_{i, t}$, can therefore be defined as

$$
y_{i, t}=y_{i, t}^{m}+y_{i, t}^{u}
$$

According to Eq. (3), a firm is always allowed to produce a total output of $y_{i, t}$ using only regular technology. Unofficial productive factors are therefore not strictly necessary to produce the firm's final output. As a result, underground production in our model takes place primarily because firms aim to take advantage of the opportunity of tax evasion that it provides.

In our model, capital and labor markets are perfectly competitive. Firms pay the rental rates $r_{t}^{m}$ and $r_{t}^{u}$ to rent a unit of capital from the regular and unofficial market, respectively. The cost of labor in the regular market is given by the wage paid for one unit of labor services $w_{t}^{m}$, augmented by a stochastic social security tax rate $\tau_{t}^{S}<1$, while the cost of labor hired in the underground market is given by the wage, $w_{t}^{u}$. Accordingly, the total costs for a firm $i$, namely TC, are defined as follows:

$$
\operatorname{TC}\left(h_{i, t}^{m}, h_{i, t}^{u}, k_{i, t}^{u}, k_{i, t}^{m}\right)=\left(1+\tau_{t}^{S}\right) w_{t}^{m} h_{i, t}^{m}+w_{t}^{u} h_{i, t}^{u}+r_{t}^{u} k_{i, t}^{u}+r_{t}^{m} k_{i, t}^{m}
$$

To discourage concealed transactions, the government enforces a monitoring process. Following Allingham and Sadmo (1974), we assume that on each date $t$, firms face a stochastic probability $p_{t} \in(0,1)$ of being inspected and forced to pay the tax rate $\tau_{t}^{c}$ on the concealed production (net of labor costs), augmented by a penalty surcharge factor $s>1$. As a result, net revenues from an amount of final output $y_{i, t}$ at time $t$ is a random variable described by the following expression:

$$
N R\left(y_{i, t}\right)= \begin{cases}y_{i, t}^{m}-\tau_{t}^{c}\left(y_{i, t}^{m}-w_{t}^{m} h_{i, t}^{m}\right)+y_{i, t}^{u}-s \tau_{t}^{c}\left(y_{i, t}^{u}-w_{t}^{u} h_{i, t}^{u}\right) & \text { if detected } \\ y_{i, t}^{m}-\tau_{t}^{c}\left(y_{i, t}^{m}-w_{t}^{m} h_{i, t}^{m}\right)+y_{i, t}^{u} & \text { otherwise }\end{cases}
$$

Accordingly, expected net revenues can be written as follows:

$$
E\left(N R\left(y_{i, t}\right)\right)=\left(1-\tau_{t}^{c}\right) y_{i, t}^{m}+\left(1-p_{t} s \tau_{t}^{c}\right) y_{i, t}^{u}+p_{t} s \tau_{t}^{c} w_{t}^{u} h_{i, t}^{u}+\tau_{t}^{c} w_{t}^{m} h_{i, t}^{m}
$$

The optimal amount of final output produced by a firm $i$ at date $t$ is thus the solution of the following static problem:

$$
\left\{\begin{array}{l}
\max _{h_{i, t}^{m}, h_{i, t}^{u}, k_{i, t}^{m}, k_{i, t}^{u}} E_{t}\left\{N R\left(y_{i, t}\right)\right\}-T C\left(h_{i, t}^{m}, h_{i, t}^{u}, k_{i, t}^{m}, k_{i, t}^{u}\right) \\
\text { s.t. } \\
y_{i, t}^{m}=A_{t}\left(\Gamma_{t} h_{i, t}^{m}\right)^{\alpha}\left(k_{i, t}^{m}\right)^{1-\alpha} \\
y_{i, t}^{u}=B_{t}\left(\Gamma_{t} h_{i, t}^{u}\right)^{\alpha_{u}}\left(k_{i, t}^{u}\right)^{1-\alpha_{u}}
\end{array}\right.
$$

where $E_{t}$ denotes the mathematical expectation operator conditional on information available at time $t$. The associated optimal planning satisfies the following four conditions, which describe optimal demands for factors supplied in both regular and underground markets:

$$
(1-\alpha) \frac{y_{i, t}^{m}}{k_{i, t}^{m}}=\frac{r_{t}^{m}}{1-\tau_{t}^{c}}
$$

\footnotetext{
2 An alternative way to introduce this property into the model is to assume that goods produced in the two sectors are manufactured with the same technology but firms have to pay an additional cost for every unit of underground output produced. We prefer to rely on sector-specific production functions to take into account the labor-intensive nature of underground production activities.

3 This supposes that customers in the regular markets are unable to detect which products are manufactured by irregular workers. While realistic for commodities, this hypothesis is somewhat too restrictive in the case of specific services where underground transactions often result from direct agreements between customers and producers. In these circumstances, the cost to the customer of regular and underground services cannot be equal at equilibrium. One way to incorporate this feature into our framework is to specify a service sector in which firms face a different demand for underground and regular services, and customers pay value added taxes only on the latter. We, however, decided to abstract from this possibility because tax evasion of this nature is likely to be quantitatively negligible.
} 


$$
\begin{aligned}
& \alpha \frac{y_{i, t}^{m}}{h_{i, t}^{m}}=\frac{w_{t}^{m}\left(1+\tau_{t}^{s}-\tau_{t}^{c}\right)}{1-\tau_{t}^{c}} \\
& \left(1-\alpha_{u}\right) \frac{y_{i, t}^{u}}{k_{i, t}^{u}}=\frac{r_{t}}{1-p_{t} s \tau_{t}^{c}} \\
& \alpha_{u} \frac{y_{i, t}^{u}}{h_{i, t}^{u}}=w_{t}^{u}
\end{aligned}
$$

Eq. (6) indicates that the condition $1-p_{t} s \tau_{t}^{c}>0$ is necessary for an interior solution with underground production. Intuitively, when $1-p_{t} s \tau_{t}^{c} \leqslant 0$, firms have no incentive to use irregular factors to produce final output because the real revenues from the underground sector are expected to be negative. In this case, total output is entirely produced with regular technology (i.e., $h_{i, t}^{u}=k_{i, t}^{u}=0$ ), and therefore, firms do not evade taxation.

\subsection{The representative household}

The representative household has preferences in period 0 given by:

$$
U_{t}^{h}=\sum_{t=0}^{\infty} \beta^{t} E_{0}\left\{\frac{\left(c_{t} / \Gamma_{t}\right)^{(1-\sigma)}-1}{1-\sigma}-\xi_{t}^{h} B_{0} \frac{\left(h_{t}^{m}+h_{t}^{u}\right)^{1+\xi}}{1+\xi}-B_{1} \frac{\left(h_{t}^{u}\right)^{1+\phi}}{1+\phi}\right\}
$$

where $\sigma>0$ is the inverse of the intertemporal elasticity of substitution, $\beta \in(0,1)$ is the subjective discount factor, $B_{0} \geqslant 0$ and $B_{1} \geqslant 0$ are preference parameters controlling for the disutility of working activities, and $\xi>0$ and $\phi>0$ respectively denote the inverse labor supply elasticities of aggregate and underground labor supplies. $\xi_{t}^{h}$ represents a purely transitory labor supply shock that affects the marginal rate of substitution between consumption and leisure.

The specification of preference implies that households derive utility from consumption relative to the rate of technology $\Gamma_{t}$. This assumption ensures that the economy evolves along a balanced growth path. As in An and Schorfheide (2007), we interpret $\Gamma_{t}$ as an exogenous habit component. The specification of the disutility of labor is adapted from Cho and Rogerson (1988) and Cho and Cooley (1994). In their models, the authors distinguish households' labor supply along the intensive/extensive margin. As in Busato and Chiarini (2004), we reinterpret these margins in terms of labor supply in the regular and underground market. Accordingly, the first component of the disutility of labor captures the effect of total hours worked $\left(h_{t}^{m}+h_{t}^{u}\right)$. Its specification is standard in the RBC literature, and allows for perfect labor mobility across sectors. The second component, in contrast, introduces a specific cost for the households of working in the underground sector. This additional cost may be interpreted as capturing the cost associated with the lack of any social and health insurance in the underground sector. ${ }^{4}$

Households supply labor services per unit of time and rent to firms whatever capital they own. We assume that the capital stock, $k_{t}$, held by households evolves over time according to the following law of motion

$$
k_{t+1}=\xi_{t}^{x} x_{t}+\left(1-\delta_{k}\right) k_{t}
$$

where $x_{t}$ denotes the investment at date $t$, and $\delta_{k} \in[0,1]$ is the capital depreciation rate. Following Justiniano et al. (2010), we assume that the efficiency with which the final good can be transformed into physical capital is random and determined by the purely transitory exogenous shock $\xi_{t}^{X}$. As shown in Greenwood et al. (1988), a stochastic disturbance of this type is equivalent to a sector-specific technological shock which affects the production of investment goods in a simple two-sector model. As such, this assumption is useful in capturing the potentially different sources of fluctuations between consumption and investment.

Households might evade income taxes by reallocating their labor services from the regular to the irregular labor markets, and by supplying capital in the underground market. Underground-produced income flows, $w_{t}^{u} h_{h, t}^{u}+r_{t}^{u} k_{t}^{u}$, are therefore not subject to the stochastic income tax rate $\tau_{t}^{h}<1$. Under these assumptions, households' period-by-period budget constraint can be written as follows:

$$
c_{t}+x_{t}=\left(1-\tau_{t}^{h}\right)\left(w_{t}^{m} h_{t}^{m}+r_{t}^{m} k_{t}^{m}\right)+w_{t}^{u} h_{t}^{u}+r_{t}^{u} k_{t}^{u}
$$

where the capital stocks supplied by households in the regular and underground markets satisfy:

$$
k_{t}^{u}+k_{t}^{m}=k_{t}
$$

The utility maximization problem for the representative household can then be stated as a matter of choosing the processes $c_{t}, h_{t}^{u}, h_{t}^{m}, k_{t}^{m}$ and $k_{t}^{u}$ which maximize the intertemporal utility function, $U_{t}^{h}$, subject to the constraints given

\footnotetext{
4 Notice that the specification of disutility of labor implies wage-differentials across the regular and underground labor markets. We have found empirical evidence supporting wage differentials from Italian Households Survey data provided by Bank of Italy. Results are available upon request.
} 
by Eqs. (8)-(10). An optimal consumption, labor supply, and saving plan for the representative household must satisfy the following conditions:

$$
\begin{aligned}
& \frac{\lambda_{t}}{\xi_{t}^{x}}=\beta E_{t}\left\{\lambda_{t+1}\left[\frac{\left(1-\delta_{k}\right)}{\xi_{t+1}^{X}}+\left(1-\tau_{t+1}^{h}\right) r_{t+1}^{m}\right]\right\} \\
& B_{0}\left(h_{t}^{m}+h_{t}^{u}\right)^{\xi} \xi_{t}^{h}=\left(1-\tau_{t}^{h}\right) w_{t}^{m} \lambda_{t} \\
& B_{0}\left(h_{t}^{m}+h_{t}^{u}\right)^{\xi} \xi_{t}^{h}+B_{1}\left(h_{t}^{u}\right)^{\phi}=w_{t}^{u} \lambda_{t} \\
& r_{t}^{u}=\left(1-\tau_{t}^{h}\right) r_{t}^{m}
\end{aligned}
$$

where $\lambda_{t}=\Gamma_{t}^{(\sigma-1)} c_{t}^{-\sigma}$ is the Lagrange multiplier for the constraint (9). Eq. (11) is the usual Euler equation which provides the intertemporal optimality condition, while Eq. (12) describes the (total) labor supply schedule. Eq. (14) determines the optimal allocation of capital supplied to the irregular market, implying that at equilibrium the real rate $r_{t}^{u}$ must equate to the net-of-tax rental rate of regular capital. Finally, Eq. (13) describes the optimal allocation of time for working activities in the underground sector. In order to understand what the determinants of the irregular labor supply are, it is useful to combine (12) with (13) and solve the resulting equation with respect to $h_{t}^{u}$ to obtain the following:

$$
h_{t}^{u}= \begin{cases}\lambda_{t}^{\frac{1}{\phi}}\left[\frac{w_{t}^{u}-\left(1-\tau_{t}^{h}\right) w_{t}^{m}}{B_{1}}\right]^{\frac{1}{\phi}} & \text { if } w_{t}^{u}-\left(1-\tau_{t}^{h}\right) w_{t}^{m}>0 \\ 0 & \text { otherwise }\end{cases}
$$

This equation states that households supply labor services in the underground sector as long as the wage that they earn from this activity exceeds the net real wage that they earn by working in the regular labor market. In this perspective, $1 / \phi$ stands for the Frisch elasticity of irregular labor supply with respect to the net-of-tax wage differential between the underground and the regular labor market. Additionally, for a given wage differential, the supply of irregular labor shifts to the left when parameter $B_{1}$ increases. Intuitively, to keep the same amount of irregular labor supplied, households require a higher wage gap to compensate for the increased disutility that they derive from working in the irregular sector.

\subsection{Government}

In each period $t$, the government raises taxes to finance a given amount of government consumption, $g_{t}$. For the sake of simplicity, we abstract from public debt and assume that public expenditures are selected on a balanced basis for each period. The period-by-period government budget constraint can then be written as follows:

$$
g_{t}=\tau_{t}^{h}\left(w_{t}^{m} h_{t}^{m}+r_{t}^{m} k_{t}^{m}\right)+\tau_{t}^{c} \int_{0}^{1}\left[y_{i, t}^{m}-w_{t}^{m} h_{i, t}^{m}+p_{t} s\left(y_{i, t}^{u}-w_{i, t}^{u} h_{i, t}^{u}\right)\right] d i+\tau_{t}^{s} w_{t}^{m} \int_{0}^{1} h_{i, t}^{m} d i
$$

where the first term on the right-hand side of the above equation is total fiscal revenues from personal income taxation, $G_{t}^{h}$, the second term is total fiscal revenues from corporate taxation, $G_{t}^{c}$; and the last term is total fiscal revenues from social security contributions, $G_{t}^{s}$. Accordingly, total tax evasion at date $t$, namely $T E_{t}$, takes the following form:

$$
T E_{t}=\tau_{t}^{s} w_{t}^{u} \int_{0}^{1} h_{i, t}^{u} d i+\tau_{t}^{h}\left(w_{t}^{u} h_{t}^{u}+r_{t}^{u} k_{t}^{u}\right)+\left(1-p_{t}\right) \tau_{t}^{c} \int_{0}^{1}\left(y_{i, t}^{u}-w_{t}^{u} h_{i, t}^{u}\right) d i
$$

\subsection{Stochastic processes}

To complete the model, we formulate productivity, fiscal and other disturbances as a stationary VAR(1) process

$$
\mathbf{z}_{t}=(I-\Phi) \mathbf{z}+\Phi \mathbf{z}_{t-1}+\varepsilon_{t}
$$

where $\mathbf{z}_{t}=\left\{\ln \left(A_{t}\right), \ln \left(B_{t}\right), \ln \left(\tau_{t}^{c}\right), \ln \left(\tau_{t}^{S}\right), \ln \left(\tau_{t}^{h}\right), \ln \left(\xi_{t}^{i}\right), \ln \left(\xi_{t}^{h}\right), \ln \left(p_{t}\right)\right\}^{\prime}, \mathbf{z}$ is a vector containing the mean values of the exogenous state variables, $\Phi=\operatorname{diag}\left[\rho_{a}, \rho_{b}, \rho_{c}, \rho_{s}, \rho_{h}, \rho_{H}, \rho_{I}, \rho_{p}\right]$, and $\varepsilon_{t}=\left\{\varepsilon_{t}^{a}, \varepsilon_{t}^{b}, \varepsilon_{t}^{c}, \varepsilon_{t}^{s}, \varepsilon_{t}^{h}, \varepsilon_{t}^{I}, \varepsilon_{t}^{H} \text {, } \varepsilon_{t}^{p}\right\}^{\prime}$ is the vector of zeromean normal random innovations with diagonal variance covariance matrix $\Omega=\operatorname{diag}\left[\sigma_{a}^{2}, \sigma_{b}^{2}, \sigma_{c}^{2}, \sigma_{s}^{2}, \sigma_{h}^{2}, \sigma_{H}^{2}, \sigma_{I}^{2}, \sigma_{p}^{2}\right]$.

\subsection{Symmetric equilibrium}

We restrict our analysis to symmetric equilibria where all firms produce the same quantity of their respective good using the same amount of official and irregular productive factors. The symmetric equilibrium of the model is then formally derived by imposing the following clearing conditions for the goods, the labor and the capital markets: 


$$
\begin{aligned}
& c_{t}+x_{t}+g_{t}=\int_{0}^{1} y_{i, t} d i \\
& h_{t}^{u}=\int_{0}^{1} h_{i, t}^{u} d i ; \quad h_{t}^{m}=\int_{0}^{1} h_{i, t}^{m} d i \\
& k_{t}^{u}=\int_{0}^{1} k_{i, t}^{u} d i ; \\
& k_{t}^{m}=\int_{0}^{1} k_{i, t}^{m} d i
\end{aligned}
$$

Given the assumptions made for production functions and preferences, the model's economy features a balanced growth path equilibrium in which the variables grow at a constant rate. It is therefore convenient to express the model in terms of detrended variables for which a deterministic steady state exists. Thus, denoting with $\hat{S}_{t}=S_{t} / \Lambda_{t}$ the original variable $S_{t}$ detrended by means of its trend $\Lambda_{t}$, imposing the clearing condition in each market, and letting $\mathbf{x}_{t}=\left(\hat{r}_{t}^{m}, \hat{w}_{t}^{m}, \hat{w}_{t}^{u}, \hat{r}_{t}^{u}, \hat{y}_{t}^{m}, \hat{y}_{t}^{u}, \hat{h}_{t}^{m}, \hat{h}_{t}^{u}, \hat{G}_{t}^{c}, \hat{G}_{t}^{s}, \hat{G}_{t}^{h}, \hat{c}_{t}, \hat{k}_{t}, \hat{x}_{t}, \hat{y}_{t}, \hat{k}_{t}^{u}, \hat{k}_{t}^{m}\right)$ be the vector of all endogenous variables, a symmetric equilibrium for the economy can be formally defined as an initial condition $\hat{k}_{0} \in \mathbb{R}_{+}$and a process $\left\{\mathbf{x}_{t}\right\}_{t=0}^{\infty}$ which, given the exogenous stochastic process $\left\{\mathbf{z}_{t}\right\}_{t=0}^{\infty}$, satisfies Eqs. (1)-(14) and

$$
\begin{aligned}
& \hat{G}_{t}^{h}=\tau_{t}^{h}\left(\hat{w}_{t}^{m} \hat{h}_{t}^{m}+\hat{r}_{t}^{m} \hat{k}_{t}^{m}\right) \\
& \hat{G}_{t}^{c}=\tau_{t}^{c}\left[p_{t} s\left(\hat{y}_{t}^{u}-\hat{w}_{t}^{u} \hat{h}_{t}^{u}\right)+\hat{y}_{t}^{m}-\hat{w}_{t}^{m} \hat{h}_{t}^{m}\right] \\
& \hat{G}_{t}^{s}=\tau_{t}^{s} \hat{w}_{t}^{m} \hat{h}_{t}^{m}
\end{aligned}
$$

\section{Parameter estimates}

\subsection{Methods and data}

Inference is a major issue when managing DSGE models. Here, we recur to Bayesian estimation methods, and in particular to MCMC algorithms, which have proved to be successful in the empirical macroeconomic literature (see e.g. Smets and Wouters, 2007; Canova and Sala, 2009; Fernandez-Villaverde and Rubio-Ramirez, 2007). Due to the nonlinearity of Eqs. (1)-(17), the model was first linearized and then solved by means of the algorithm implemented in Sims (2002). This procedure makes it possible to define a linear and Gaussian state-space system for which the likelihood can be computed in closed form. Our goal is to jointly estimate the structural parameters together with the dynamics of the non-observable economic variables. In particular, we aim to evaluate the magnitude and the dynamics of the underground economy in Italy. This task can be easily handled using a Random Walk Metropolis-Hastings algorithm. All of the calculations in this paper are based on software written using the $0 x^{\circledR} 6.21$ language of Doornik (2001) combined with the state space library ssfpack of Koopman et al. (1999) and the LiRE library to solve rational expectation systems of Mavroeidis and Zwols (2007). We build a multi-chain MCMC procedure based on 4 chains of size 200000.

We consider the following measurement equations to link our theoretical model to the real-world economy

$$
\mathbf{y}_{t} \equiv\left[\begin{array}{c}
\Delta c_{t} \\
\Delta x_{t} \\
\Delta G_{t}^{c} \\
\Delta G_{t}^{s} \\
\Delta G_{t}^{h} \\
\Delta w_{t}^{h} \\
\ln \left(p_{t}\right)
\end{array}\right]=\left[\begin{array}{c}
\gamma^{(Q)} \\
\gamma^{(Q)} \\
\gamma^{(Q)} \\
\gamma^{(Q)} \\
\gamma^{(Q)} \\
\gamma^{(Q)} \\
100 \ln (p)
\end{array}\right]+100\left[\begin{array}{c}
\hat{c}_{t}-\hat{c}_{t-1} \\
\hat{x}_{t}-\hat{x}_{t-1} \\
\hat{G}_{t}^{c}-\hat{G}_{t-1}^{c} \\
\hat{G}_{t}^{s}-\hat{G}_{t-1}^{s} \\
\hat{G}_{t}^{h}-\hat{G}_{t-1}^{h} \\
\hat{w}_{t}^{h}-\hat{w}_{t-1}^{h} \\
\hat{p}_{t}
\end{array}\right]
$$

in which $\Delta c_{t}$ is consumption growth expressed in percentage terms, $\Delta x_{t}$ is investment growth, $\Delta w_{t}^{h}$ is the change in the total gross real earnings paid in the regular market (i.e. $\left.w_{t}^{h}=\left(1+\tau_{t}^{s}\right) w_{t}^{m} h_{t}^{h}\right), \Delta G_{t}^{i}, i=c, s, h$ are the growth rates of fiscal revenues from corporate taxation, social security contributions and personal income taxation, respectively, and $p_{t}$ is the proportion of firms inspected, a proxy of the probability of being monitored. Furthermore, $\gamma^{(Q)}=100 \ln (\gamma)$ is the common quarterly trend growth rate and $p$ is the average probability of being inspected by the authority.

The model is estimated using quarterly data for the period from 1982:1 to 2006:4. Data for consumption, investment, wages and fiscal revenues are provided by the Italian National Institute of Statistics (ISTAT). ${ }^{5}$ Before the estimation, these

\footnotetext{
5 ISTAT provides annual data on fiscal revenues and labor earnings. Quarterly figures for these series are made available by Associazione Prometeia.
} 
data are deflated by the implicit GDP deflator (base year 2000) and divided by the total population aged 15-64. The proportion of fiscal controls, $p_{t}$, is the ratio between the number of inspections and the number of companies on a yearly basis. This time series is provided by the Agenzia delle Entrate (the Italian revenue agency) and has been disaggregated to a quarterly frequency using the methodology described in Proietti (2006). ${ }^{6}$

The choice of the observable variables in (18) is directly guided by the theory. More specifically, given that our ultimate goal is to estimate the size and trend of the underground economy, we choose as our observables those aggregates which, according to our model, are particularly informative regarding the magnitude of underground economic activities. In this respect, aggregate consumption and investment data proxy for the general level of economic activity in Italy; the fiscal revenue data capture the incentives of firms and households to engage in underground transactions, the official labor earnings data provide information about households' opportunity cost of supplying labor services in the underground sector, while finally the proportion of firms inspected captures the trade-off between the tax evasion benefits deriving from underground activity and the cost of being caught.

\subsection{Prior distributions and calibrated parameters}

Our prior choices are summarized in Table 1. Overall, we considered prior densities that match the domain of the structural parameters. For the parameters that are commonly used in the DSGE literature, our prior choice is consistent with previous studies (An and Schorfheide, 2007; Smets and Wouters, 2007, and Iacoviello and Neri, 2010 among others). More specifically, we assume that the inverse of the intertemporal elasticity of substitution $\sigma$ and the inverse of the elasticity of total labor supply $\xi$ are distributed according to a gamma random variable, both with mean 1 and standard deviation 0.05 . The elasticity of labor in regular production function $\alpha$ is beta with mean 0.65 and standard deviation 0.01 . The capital depreciation rate $\delta_{k}$ is beta centered at a quarterly rate of 2.5 percent and with standard deviation 0.01 . Finally, the common quarterly trend growth rate, $\gamma^{Q}$, is Gaussian with mean 0.23 and standard deviation 0.2 . The prior mean is chosen to match the average growth rate of actual per-capita GDP over the 1982-2006 period. This choice is consistent with the balanced growth path hypothesis.

Regarding the underground economy-related parameters, our priors are mostly based on previous analysis provided by ISTAT. More specifically, the elasticity of labor in the underground production function, $\alpha_{u}$, is assumed to be a beta random variable with mean 0.6587 and standard deviation 0.01 , while the disutility of working activities in the underground economy, $B_{1}$, is gamma with mean 324.43 and standard deviation 10. Conditional on all of the other prior parameter averages, the prior means of $\alpha_{u}$ and $B_{1}$ imply a steady-state size of the underground economy $\left(Y^{u} / Y\right)$ and a steady-state share of the total number of hours worked that are ascribed to the underground sector $\left(H^{u} / H\right)$ of $19 \%$ and $13 \%$, respectively. These numbers match the estimates of the underground output-to-GDP ratio and the irregular labor share provided by ISTAT over the 1999-2006 period. We believe these estimates are the most reliable available regarding the underground economy in Italy. For this reason, these values have been chosen as the starting point for our analysis. The inverse of the Frisch elasticity of underground labor supply $\phi$ is described by a gamma distribution with mean 1 and standard deviation 0.05 . A priori, the size of this parameter is equivalent to the elasticity of the total labor supply $\xi$ defined above. This choice stresses our a priori lack of knowledge regarding which of the two labor supplies is characterized by the greatest elasticity. Furthermore, the probability $p$ that a company is inspected is beta with expected value $3 \%$, corresponding to the estimate reported by Busato and Chiarini (2004) using data on the number controls published by the Italian Ministry of Labor.

For the exogenous processes, we assume that the standard errors of the innovations follow a relatively dispersed inverse gamma distribution, reflecting the lack of a priori information about these quantities. The persistence of the AR(1) processes (i.e. parameters $\rho_{a}, \rho_{b}, \rho_{c}, \rho_{h}, \rho_{s}, \rho_{H}, \rho_{I}$ and $\rho_{p}$ ) are instead described by beta distributions with means ranging between 0.5 and 0.9 to allow for moderate-to-high persistence for the propagation mechanism of the exogenous shocks. In particular, the variances of these priors are relatively high to account for a wide range of possible posterior values for these parameters.

Finally, the remaining parameters are fixed, either because they reflect certain characteristics which are regulated ex ante by law or because they are difficult to identify. More specifically, the steady-state parameters $\tau_{c}$, $\tau_{h}$ and $\tau_{s}$, representing the average tax rates on corporate profits and personal income and the rate of social security contributions, respectively, are set at $41.55 \%, 34.26 \%$ and $21 \%$. These numbers are consistent with the average tax rates in Italy over the $1982-2006$ period. ${ }^{7}$ Furthermore, the penalty paid by a firm once detected is set at $30 \%$ of the corporate tax rate. The penalty surcharge factor is thus $s=1.30$, that is consistent with the current Italian Tax Law (Busato and Chiarini, 2004). ${ }^{8}$ The subjective discount factor $\beta$ is set to 0.9840 , implying a steady-state gross interest rate of 1.0186 . Finally, the parameter controlling for the disutility of the total labor supply, $B_{0}$, has been set to a value that implies that households devote $19 \%$ of their

\footnotetext{
6 As a leading indicator we used the fiscal revenues obtained from the monitoring activity. We would like to thank the Agenzia delle Entrate for also providing us with this variable.

7 Specifically, the average tax rate on personal income and the rate of social security contributions are taken from Busato and Chiarini (2004), while the value for $\tau_{c}$ corresponds to the average Italian statutory corporate tax rate over the 1982-2006 period. The values for statutory tax rates are taken from the OECD Tax Database. For the 1998-2006 period, the OECD figures have been increased by $4.25 \%$ to account for the newly-introduced regional corporate taxation (IRAP).

8 A number of sensitivity analyses on this parameter suggest that different levels of $s$, ranging between 1.25 and 1.40 , provide similar results in terms of estimates and policy implications of the model. Results are available upon request.
} 
Table 1

DSGE with underground economy - Posterior computation (MCMC).

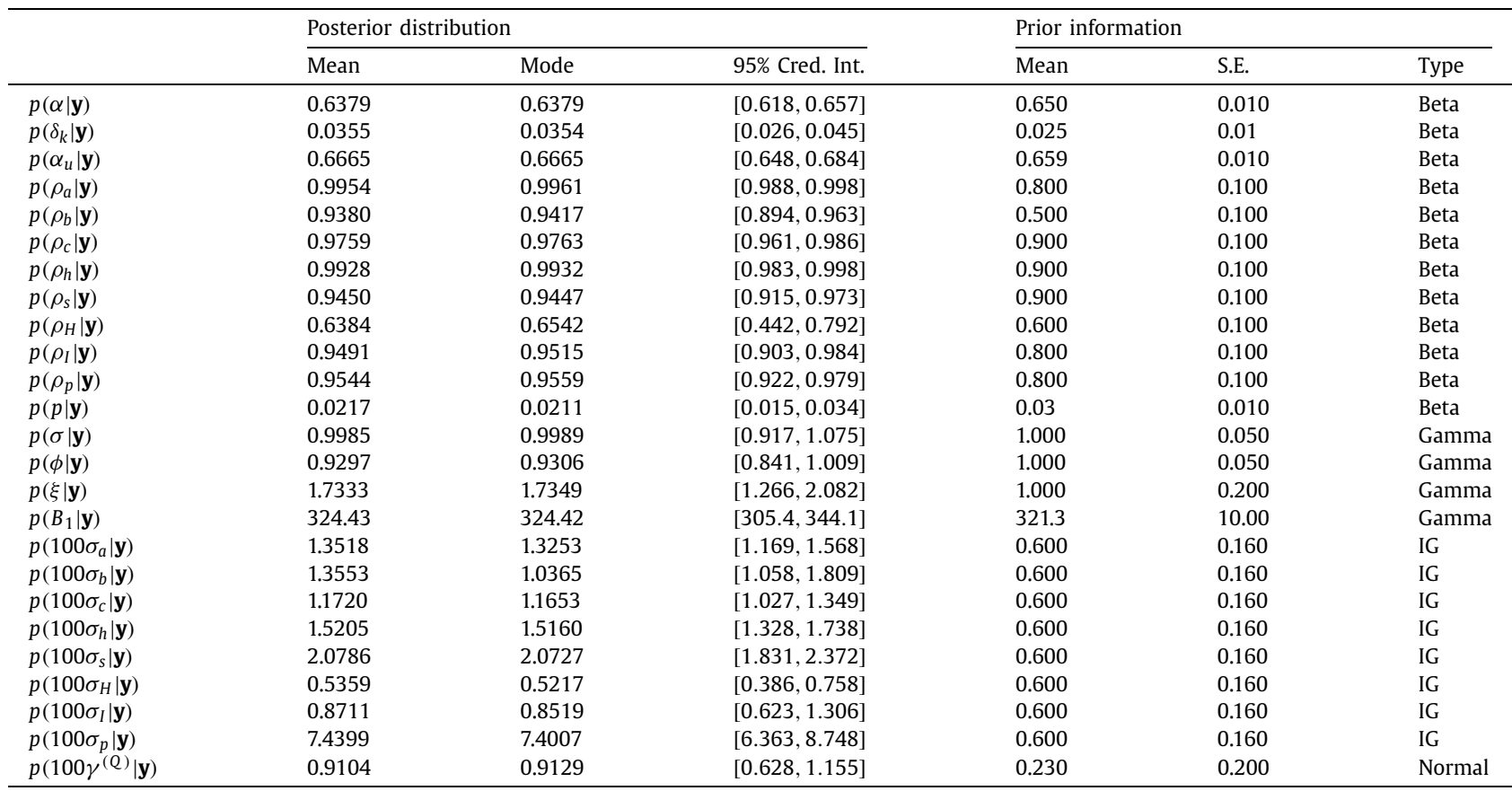

time to labor activities. This value corresponds to the average hours worked in a quarter as a fraction of the total quarterly hours for the 1982-2006 period. In the estimation procedure, parameter $B_{0}$ is updated at any iteration through the formula $B_{0}=\left(1-\tau_{s s}^{h}\right) w_{s s}^{m} c_{s s}^{-\sigma}\left(h_{s s}^{m}+h_{s s}^{u}\right)^{-\xi}$.

\subsection{Posterior distributions}

Table 1 shows the posterior mean, mode, and 95 percent probability interval for the structural parameters, together with the mean and standard deviation of the prior distributions. ${ }^{9}$ A commonly-used, practical way to assess the identification of the parameters is to compare the prior to the posterior distributions to check if the observable variables are informative for inferential purposes. These results are displayed in Fig. 6 below, in Appendix A.

On closer inspection, the posterior estimates of the parameters governing production show a negative shift for $\alpha$ in which the posterior average is reduced to 0.63 with respect to the a priori expected value of 0.65 , while we observe a positive variation of $\alpha_{u}$, for which the center of the posterior moves to 0.66 . These estimates provide evidence in favor of a higher output sensitivity to labor in the irregular market. Furthermore, the empirical results show that parameter $p$ is strongly identified. In particular the posterior mean decreases with respect to its prior counterpart, shifting from $3 \%$ (prior mean) to $2.17 \%$ (posterior mean), and the standard deviation of the posterior distribution shrinks substantially with respect to the prior distribution.

Regarding households, the posterior estimate of $\sigma$ is slightly smaller than its prior counterpart, suggesting that consumption is somewhat more sensitive to movements in the real interest rate with respect to what is implied by our prior hypothesis. With respect to the prior assumptions, the estimate of labor supply elasticity in the regular market $\xi$ substantially increases (1.733), while its counterpart in the irregular market $\phi$ is slightly reduced on average (0.929). These findings suggest that labor supply in the underground sector is more sensitive to movements in the wage rate than labor supply in the regular sector. The estimated $\delta_{k}(0.035)$ implies a half-life for capital stock of about 5 years. The parameter controlling for the disutility of irregular labor, $B_{1}$, has a posterior mean of 324.4, which is substantially equivalent to its prior mean.

By looking at the exogenous processes, the autoregressive coefficients are large and in some cases close to 1, thus providing strong evidence of shock persistence. The variances of the exogenous shocks are clearly identified, since the posterior distributions deviate sensibly from the prior assumptions.

\footnotetext{
9 To assess the overall goodness-of-fit of our model, we have compared our results with a DSGE-VAR specification, and with an alternative version of our model with home production. We find that impulse-response functions of the DSGE specification resemble those of the DSGE-VAR, and that the marginal likelihood of the model with underground economy (1382.43) is higher than that for the model with home production (1144.72). Results are available upon request.
} 
(A) Size and Dynamics of the Underground Economy

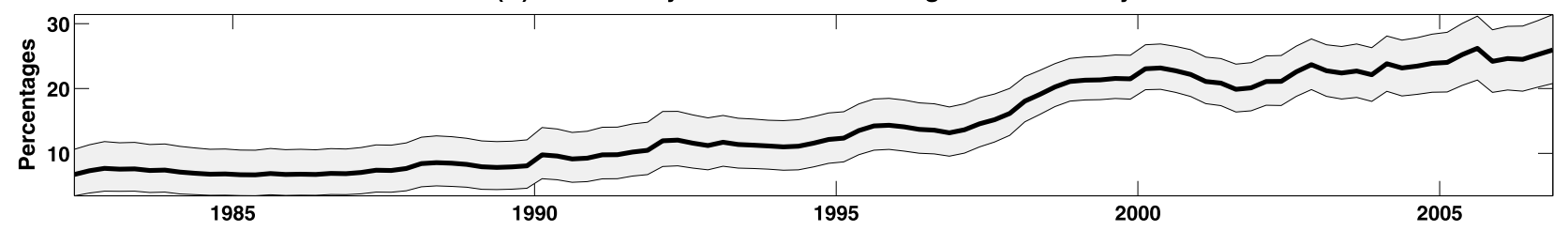

(B) Historical Decomposition

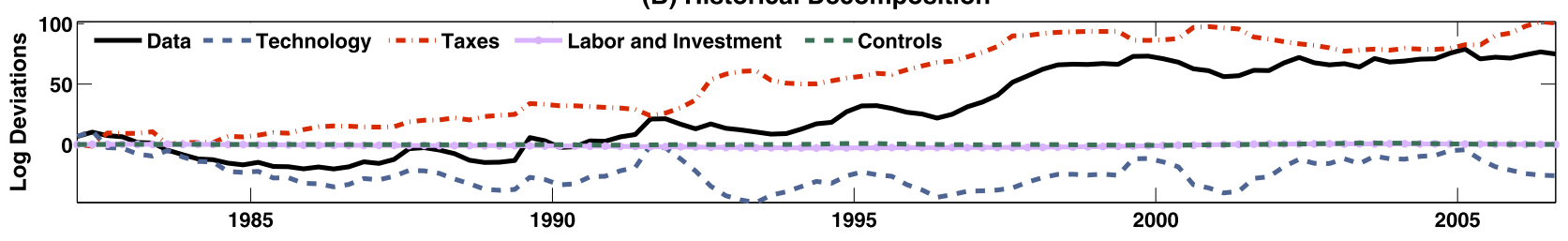

(C) Comparison

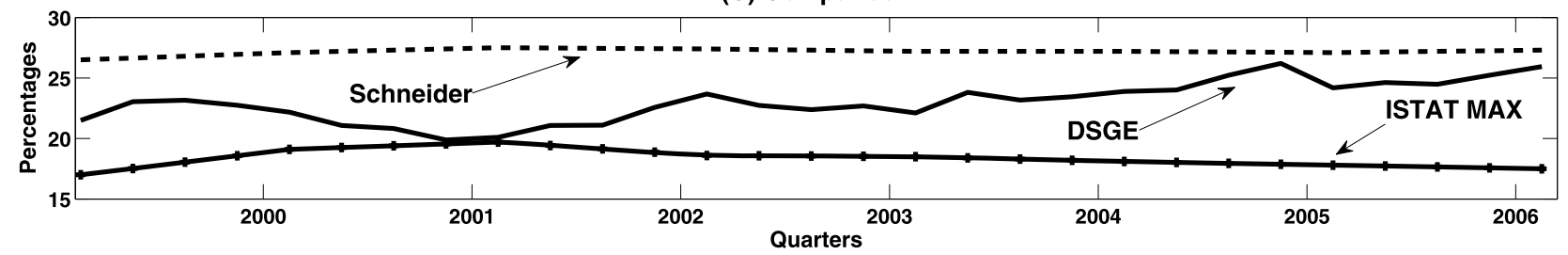

Fig. 1. Size and trend of the underground economy. Panel A: smoothed estimate of the quarterly ratio of underground production to total output together with the 95 percent credible interval. Panel B: historical decomposition of underground production-GDP ratio. Note that the technology component includes sector-specific technology shocks. The fiscal factor includes shocks regarding corporate, social security and personal income tax rates. Other shocks include labor, investments and fiscal monitoring. Panel C: comparison with other approaches. Estimates of the underground economy provided by ISTAT (maximum hypothesis), MIMIC method from Schneider and Enste (2012) [p. 38] and DSGE estimates.

Finally, a number of convergence diagnostics, available upon request, suggest that the algorithm converges within 100000 iterations to its correct expected value, and, according to these results, we discarded the first 100000 draws from each chain to remove dependence on the initial conditions.

\section{The underground economy in Italy and its causes}

Panel A of Fig. 1 depicts the smoothed estimate of the ratio of underground production to GDP along with the 95 percent credible bands. ${ }^{10}$ This figure summarizes how our model predicts the size and the trend of the underground economy in Italy over the 1982-2006 period.

There is a strong evidence of a steep increase in the size of the underground economy, leading to a significant growth over two decades. In particular, the series started the sample around the $7 \%$, and then grew slowly during the 1980 s, up to $10 \%$. After that period, the series increased quickly during the 1990 s and then fluctuated around the $20-25 \%$ from 2000 until the end of the sample. Our empirical results for the 1999-2006 period are higher than the official estimates, and confirm that the underground sector is sizeable in Italy. Additionally, the estimated model predicts two major contractions in the size of the underground economy: one between 1992 and 1994 and the second between 2000 and 2002 . In the first case, the size of the underground economy decreased by about 1 percentage point whereas in the second case the reduction was about 3 percentage points. In contrast, two major expansions occurred in the 1996-2000 period and in the 2001-2005 period, in which the underground economy increased in size by about 10 percentage points and 5 percentage points respectively.

It is of obvious interest to shed light on the sources of the predicted underground economy. To this end, panel B of Fig. 1 plots the smoothed estimates of the underground economy (in log-deviation from the steady-state) along with the historical contribution of technological and fiscal factors, controls and other shocks. This picture provides a visual representation of the relative contribution of each shock to the predicted dynamics of the underground economy in Italy. As the picture illustrates, the trend of the underground economy is clearly explained by the fiscal component (the sum of the three fiscal shocks). More specifically, it is evident that a rise in the fiscal component has led to a systematic increase in the size of the underground economy. The technological component, on the other hand, is significant mainly in explaining the variability

\footnotetext{
10 To estimate the endogenous variables dynamics, we picked all of the posterior draws from the MCMC algorithm and, for each set of these parameters, we evaluated the latent variables through the simulation smoother algorithm described in de Jong and Shephard (1995). Our posterior estimate is thus the average of all of the trajectories obtained, whereas the credible bands have been computed as the 2.5 and the 97.5 percentiles of the empirical distribution. This procedure also allows us to take into account parameter uncertainty.
} 
of the underground economy around its upward trend. By contrast, the contribution of controls and other shocks (the sum of preference and investment-specific shocks) is negligible over the whole sample period.

To understand the mechanisms behind the above predictions, it is useful to analyze how the major aggregates react to fiscal shocks. This assessment is illustrated in Fig. 5 (see Appendix A), in which we show the impulse-response functions of regular and underground production, total output (GDP), consumption, investment, and the size of the underground economy $\left(y_{t}^{u} / y_{t}\right)$ due to positive fiscal shocks. For each variable, the impulse-response functions are shown along with the 95 percent credible intervals. ${ }^{11}$ Unsurprisingly, because taxation is distortive in our framework, the estimated model suggests that increasing taxes implies a negative response of consumption, investment, and GDP. The presence of the underground economy, however, implies an additional resource reallocation effect: underground production increases, while official production declines, thereby increasing the size of the underground economy. ${ }^{12}$ This result is consistent with the findings of Basile et al. (2012) who, in estimating a VECM with Italian aggregate data, also provide evidence in favor of a resources reallocation effect caused by fiscal shocks. Most importantly, the analysis of impulse-response functions reveals that the resource reallocation effect induced by taxes is the main mechanism responsible for the predicted upward trend in the size of the underground economy. This feature is apparent in Fig. 4 (see Appendix A), which plots the smoothed estimates of each tax rate, and shows that both income and corporate tax rates (and to a lesser extent social security tax rates) increased consistently over the 1982-2006 period.

Finally, to assess the reliability of our approach, we compare our results with other estimates of the underground economy obtained using different methods. To this end, panel C of Fig. 1 reports yearly estimates from Schneider and Enste (2012) obtained using the MIMIC approach, and the official statistics (maximum hypothesis) provided by ISTAT for the 1999-2006 period. As the picture illustrates, our estimates range between the two series, although with different dynamics. Additionally, for the period from 1982 to 2000, a graphical representation provided in Dell'Anno (2003) and obtained using the MIMIC approach, evidences an upward-trending behavior of the underground economy, with a size that ranges from 10 percent during the 1980 s to about 22 percent in the 2000s. These estimates are clearly consistent with the dynamics of the underground economy reported in panel A of Fig. 1. Overall, the comparison with other methods highlights that the DSGE estimates provide a reasonable measure of size and dynamics of the underground sector in Italy. ${ }^{13}$

\section{Policy implications}

In this section, we use the estimated model to assess the effects of alternative fiscal policies. The current Italian sovereign debt crisis has strengthened the urge among Italian policy makers to design suitable policies to fight tax evasion. This issue is perceived as a priority in Italy not only because it is necessary to increase fiscal revenues to prevent the risk of national default but also because of the desire to improve fiscal equity among individuals. Given the size of the informal sector in Italy, it is clear that, in order to achieve these targets in an efficient manner, it is of fundamental importance to know how the underground economy reacts to different fiscal and institutional stimuli. In this perspective, our approach provides a natural laboratory from which to derive general equilibrium implications relating to fiscal policies.

\subsection{The Laffer curve}

According to OECD statistics, in 2009 the tax revenues to GDP ratio was $43.4 \%$ for Italy, an overall tax burden which was higher than both the OECD and the European average (respectively, 33.8\% and 37.1\%). As a result, there exists a certain consensus among Italian economists that the fiscal burden is responsible not only for tax evasion but also for discouraging foreign direct investment and weakening the competitiveness of Italian firms. In this respect, it is widely accepted that a general reduction in the tax burden would benefit the Italian economy.

A test of this claim is provided in Fig. 2, which illustrates the steady-state effects of changes in the corporate tax rate $\tau^{c}$. Keeping all of the other parameters fixed to their posterior mean values, the figure depicts total fiscal revenues (Laffer curve), tax evasion (in percentage terms, with respect to the overall amount of taxes due) and regular and total output as functions of the steady-state corporate tax rate. As illustrated in the left panel, the estimated steady-state Laffer curve (the continuous blue line) has the typical textbook inverted U-shape. This result concurs with previous studies (see e.g. Schmitt-Grohe and Uribe, 1997; Trabandt and Uhlig, 2009), which similarly show the existence of a Laffer curve in

\footnotetext{
11 As for the estimated size of the underground economy, these quantities have been computed as the posterior average of the impulse-response functions obtained for each draw of the MCMC algorithm. The credible intervals have been computed as the 2.5 and 97.5 percentiles of the empirical distributions obtained.

12 In the case of corporate taxation (first row of Fig. 5) and social security contributions (second row of Fig. 5), the resource reallocation effect results from the higher (net) expected returns from underground production; however, when considering taxes on personal income (last row of Fig. 5), the effect instead operates through a labor-supply channel. All else being equal, an increase of $\tau_{t}^{h}$ induces on impact a larger net wage-gap differential, thus pushing households to reallocate their labor services from the regular to the irregular labor market. This effect exerts downward pressure on irregular labor wages and, at the same time, upward pressure on official labor wages. As a result, firms find it cheaper to produce a larger portion of their outputs with irregular workers.

13 To assess the overall plausibility of our procedure, we have also estimated the model with data for the US economy. We find that over the period 1999-2006, the model predicts that the average size of the underground economy in Italy is about 13 percentage points larger than its US counterpart. This result conforms with the findings of Schneider and Enste (2012). Results are available upon request.
} 

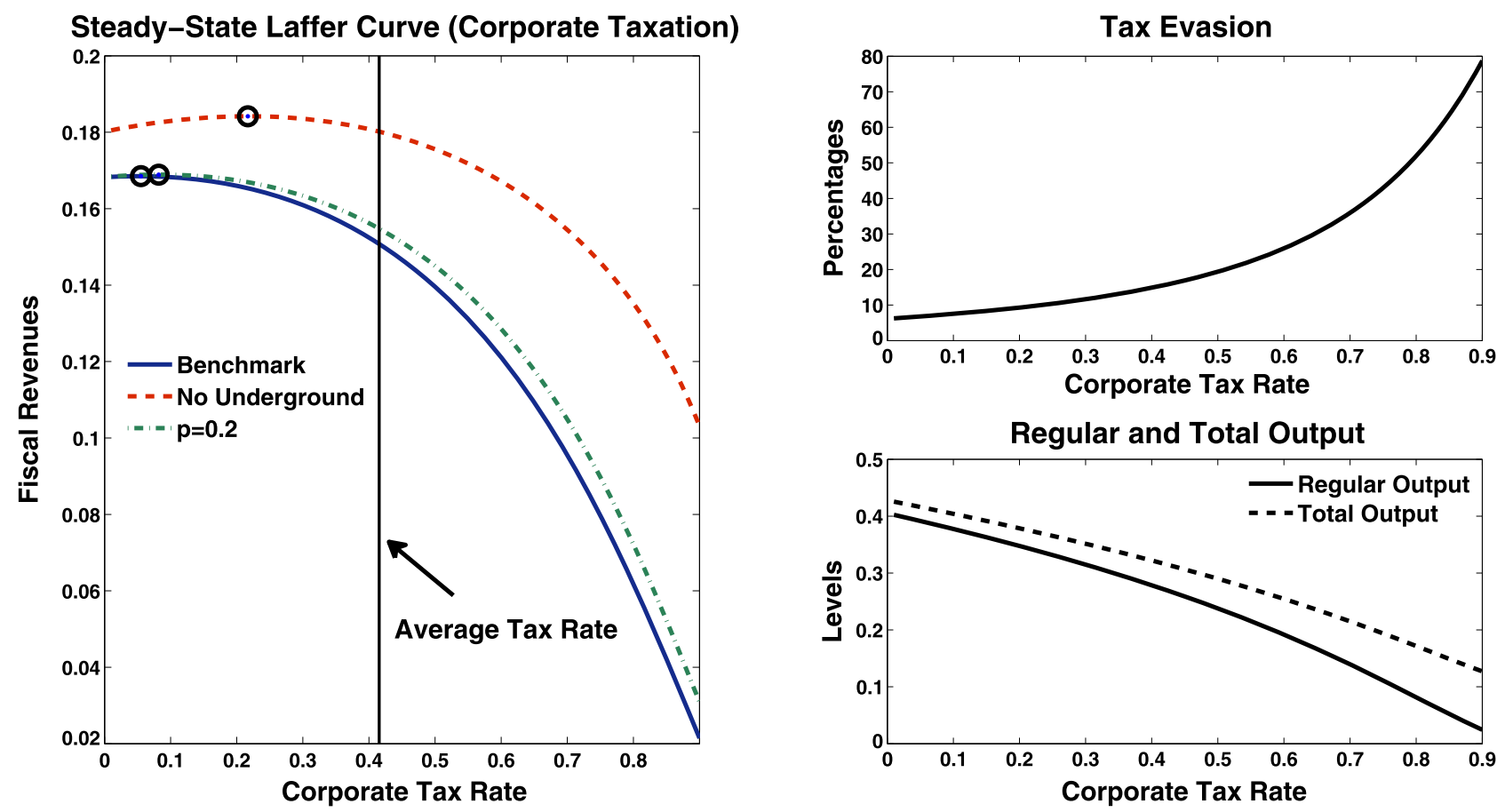

Fig. 2. Steady-state effects of corporate taxation. This picture shows the steady-state Laffer curve, total tax evasion and regular and total output as a function of the steady-state corporate tax rate $\tau^{c}$. All of the other parameters are kept fixed to their posterior mean values. Total tax evasion is expressed as a share of total taxes due.

standard neoclassical growth models. In our model, however, the shape of the Laffer curve is determined by two related effects. On the one hand, an increase in the corporate tax rate reduces the equilibrium level of regular output (see the continuous line in the right-bottom panel), thus lowering the tax base. This is the traditional effect of distortive taxation. On the other hand, concealed taxes as a share of the total tax base (a measure of the strength of tax evasion) constitute a convex function of the corporate tax rate, which increases quickly as $\tau^{c}$ moves from low to high values. This is an additional effect that is due to the presence of the underground sector in the economy. For a sufficiently large $\tau^{c}$, the above effects outweigh the one induced by a larger tax rate, thus leading to a monotonically decreasing pattern of fiscal revenues. Note that at the average corporate tax rate (the vertical line in the left panel), Italy is on the slippery side of the Laffer curve and therefore can improve its budgetary situation by cutting corporate taxes. Additionally, the figure shows that the expansion in underground production that results from higher corporate tax rates is not strong enough to completely compensate for the decline in regular output, and thus the equilibrium level of the overall production monotonically decreases with $\tau^{c}$ (see the dashed line in the right-bottom panel). Hence, the estimated model predicts that in the long run a reduction in the corporate tax rate would effectively benefit the Italian economy in terms of both higher fiscal revenues and higher total production. These results are generally confirmed in Fig. 3, which illustrates the effects upon total fiscal revenues and the economic activity of changes in the income tax rate $\tau^{h}$.

Figs. 2 and 3 also depict the steady-state Laffer curve for an economy without the underground sector (see the dashed line) ${ }^{14}$ The comparison between the complete enforcement economy and the benchmark model highlights the importance of the underground sector for fiscal policy purposes. First of all, we note that loss of fiscal revenues due to tax evasion is significant. At the average corporate tax rate, for example, the gap between revenues actually collected and potential revenues amounts to 11 percentage points of GDP, in line with the result obtained by Busato and Chiarini (2012). Furthermore, Fig. 3 shows that at the average personal income tax rate, Italy is located on the left side of the full-enforcement Laffer curve and could successfully increase tax revenues by raising the tax rate. This result contrasts with the predictions of the benchmark model, thus suggesting that lack of proper consideration for the underground sector might be severely misleading while undertaking fiscal policy interventions. In Figs. 2 and 3, we also plot the Laffer curves by setting the probability parameter $p$ to 0.2 instead of 0.0217 as in the benchmark case. This experiment is useful in assessing the effects of intensifying enforcement efforts. By comparing the continuous and dotted curves in both pictures, we see that increasing parameter $p$ has the effect of shifting the Laffer curve to the right, and thus the gap between revenues actually collected and potential revenues decreases for any given tax rate. This means that fiscal policies which credibly increase the perceived probability of being inspected and found to be evading taxes, successfully increase steady-state fiscal revenues. This result is consistent with the empirical results provided in Fiorio and Santoro (2012). In their paper, the authors use Italian data

\footnotetext{
14 The alternative Laffer curves are obtained by setting all of the parameters of the model without underground economy at their posterior mean values.
} 


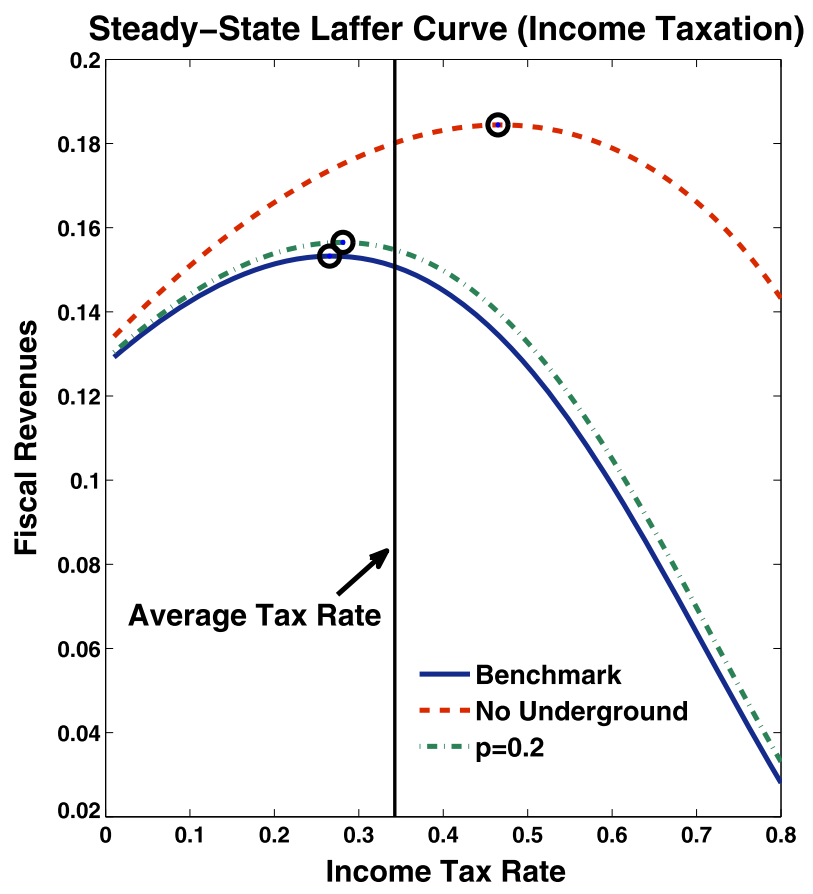

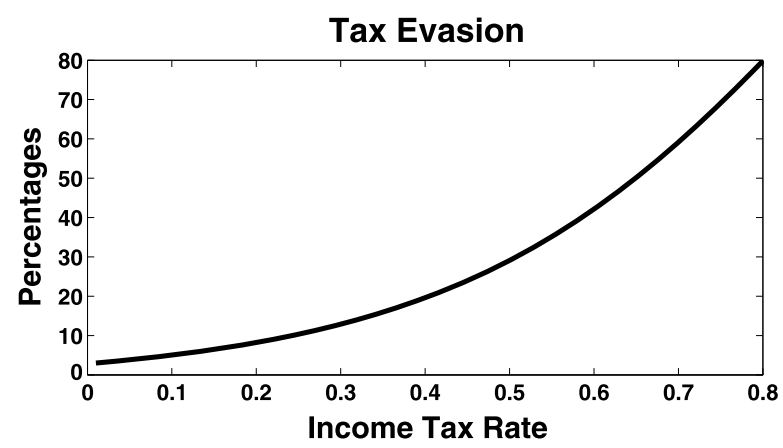

Tax Evasion

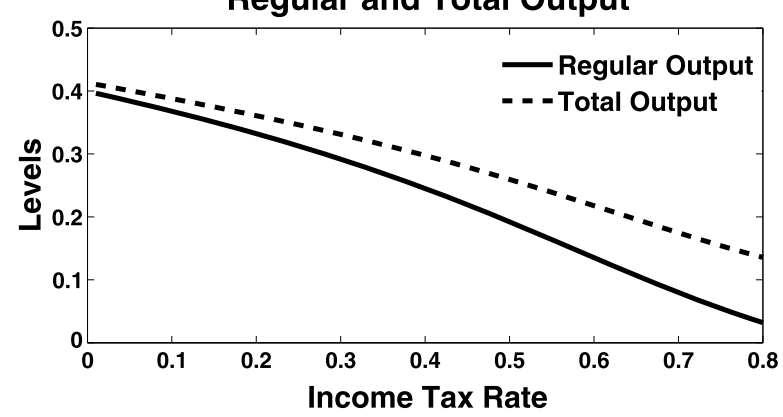

Fig. 3. Steady-state effects of personal income taxation. This picture depicts the steady-state Laffer curve, total tax evasion and regular and total output as a function of the steady-state income tax rate $\tau^{h}$. All the other parameters are kept fixed to their posterior mean values. Total tax evasion is expressed as a share of total taxes due.

Table 2

Steady-state effects and welfare implications.

\begin{tabular}{|c|c|c|c|c|c|c|c|c|c|c|}
\hline & \multicolumn{8}{|c|}{ Steady-state effects (\%) } & \multicolumn{2}{|c|}{ Welfare } \\
\hline & $\Delta G$ & $\triangle T E$ & $\Delta \frac{Y^{u}}{Y}$ & $\Delta Y^{u}$ & $\Delta Y^{m}$ & $\Delta Y$ & $\Delta C$ & $\Delta K$ & $\Delta U$ & $\frac{C e}{C_{b}}$ \\
\hline Tax cut & 1.37 & -17.7 & -15.7 & -12.0 & 7.09 & 4.40 & 7.24 & 6.83 & 3.11 & 1.06 \\
\hline Larger $p$ & 1.37 & -8.24 & -5.48 & -5.45 & 0.92 & 0.02 & -0.90 & -2.17 & -0.34 & 0.99 \\
\hline Mix & 2.52 & -24.5 & -20.4 & -16.8 & 7.91 & 4.42 & 6.47 & 4.99 & 2.85 & 1.05 \\
\hline
\end{tabular}

Note: for each variable, steady-state effects are computed as percentage deviations from their benchmark counterparts. $\Delta G$ refers to fiscal revenues.

at the firm level to assess taxpayers' response to a greater enforcement effort on the part of fiscal authorities. According to their findings, an increase in the perceived probability of being audited induces firms to increase their reported outputs and profits, thereby raising the total amount of taxes paid.

\subsection{Transitional dynamics}

We now characterize the transitional dynamics and welfare effects of three different fiscal policies: (i) a general tax cut; (ii) an increase in the monitoring effort; and (iii) a combination of both policies. We illustrate our results in Figs. 7 and 8 (see Appendix A) in which we plot the transition path of selected endogenous variables, and in Table 2 which summarizes the steady-state effects and welfare implications of each alternative fiscal policy. Welfare gains are evaluated in the steady state, as a percentage deviation of households' utility with respect to the benchmark counterpart ( $\Delta U)$, as well as over the transition path, as a ratio of equivalent consumption, $C_{e}$, to the benchmark level of steady-state consumption, $C_{b}$. For each policy, $C_{e}$ is calculated as the permanent level of consumption which provides households with the same utility that they obtain along the whole transition path.

\subsubsection{A general tax cut}

We begin our analysis by characterizing the effects of a general tax cut, assuming that each tax rate is permanently reduced by 2 percentage points. As illustrated in the first row of Table 2, a general tax cut has a positive effect on economic activity. Relative to the benchmark economy, in the new steady state, consumption, capital and GDP increase by 7.24\%, $6.83 \%$ and $4.40 \%$, respectively. The transition paths of these aggregates are depicted in Fig. 7 (see Appendix A). We see that consumption, GDP, and capital monotonically converge to the new steady state, while investment overshoots. ${ }^{15}$ The rela-

\footnotetext{
15 These dynamics resemble those of a standard neoclassical growth model due to a capital stock which is below its steady-state value.
} 
tively slow rate of convergence of these aggregates implies that, although fiscal policy has no effect on long-run growth, a general tax cut has a sustained impact on their growth rates for substantial periods during the transition. Hours worked also increase relative to the benchmark case, and this effect is due to the excess demand that occurs in the labor market because of the lower tax rates. ${ }^{16}$ However, despite the induced increase in hours worked, we find that a general tax cut is welfare-improving, both in the new steady-state $(\Delta U=3.11 \%)$, and during the whole transition path $\left(C_{e} / C_{b}=1.06\right)$. The welfare-improvement effect of the policy is clearly driven by the consumption pattern, which more than compensates for the higher disutility arising from the increased equilibrium level of hours worked. According to our results, the policy is also effective in discouraging tax evasion, which in the long run declines by $17.7 \%$. In terms of the transition, Fig. 7 (see Appendix A) shows that in the quarter immediately after the tax cut, tax evasion immediately drops below its new steady-state value, gradually increasing thereafter. This pattern mirrors the dynamic response of concealed production, which also declines in the steady state by $12.0 \%$. This last effect, together with the increase in total production, implies that the tax cut reduces the steady-state size of the underground economy ( $\Delta Y^{u} / Y$ ) by $15.7 \%$. Finally, Fig. 7 (see Appendix A) shows that fiscal revenues overshoot during the transition path, staying below the benchmark level for almost 3 years after the tax cut. This result is particularly important from the fiscal policy standpoint, as it shows that a general tax cut, despite increasing fiscal revenues in the long run, may nevertheless worsen the budgetary situation in the short run.

\subsubsection{Stronger tax enforcement}

We now assess the effects of a permanently stronger tax enforcement effort. To this end, we set the probability parameter $p$ to $11.2 \%$ instead of to $2.17 \%$, while holding the remaining parameters at their posterior mean values. The value assigned to parameter $p$ has been chosen so that, in the new steady state, total fiscal revenues are exactly the same as those resulting from the general cut tax analyzed above. This choice makes the two policies equivalent in terms of their long-run impact on fiscal revenues, and therefore facilitates comparison between them. The steady-state effects and welfare implications of the policy are reported in the second row of Table 2, while Fig. 7 (see Appendix A) illustrates the transitional dynamics. Apart from its impact on tax evasion and fiscal revenues, we note that the effects of stronger enforcement are dramatically different from those resulting from the comparable tax cut. Specifically, we observe a decline in consumption and capital in the new steady-state equilibrium, meaning that the policy has a depressionary effect on economic activity. The intuition for this result is straightforward. On the one hand, since the policy leaves tax rates unchanged, a stronger enforcement effort stimulates regular production only through the induced inter-sectorial reallocation of resources. Consequently, underground production decreases while regular production increases, but with a net effect on GDP that is virtually zero (0.02\%). On the other hand, given the balanced-budget constraint, increased fiscal revenues resulting from the policy are used by the government to finance a larger amount of wasteful public expenditures. These two effects jointly imply that the amount of resources available for the private sector decreases in equilibrium, thereby crowding out consumption and investment both in the steady state and during the whole transition path. Hours worked, in contrast, increase. However, here the effect is driven by the excess of labor supply resulting from the negative wealth effect produced by the policy. The increase in labor supply and declining consumption jointly imply that the policy has a negative impact on welfare, as summarized in Table 2. As a result, although in our model the government may completely eliminate the underground production by setting the parameters $p$ and $s$ accordingly, such a policy would nevertheless be suboptimal, as it would induce welfare losses. ${ }^{17}$ Finally, Fig. 7 (see Appendix A) shows that fiscal revenues increase by more than $2 \%$ on impact, gradually converging to the new steady state thereafter. Unlike the policy of cutting taxes, this finding shows that a permanently stronger enforcement effort increases fiscal revenues also in the very short run.

\subsubsection{Policy mix}

We shall now evaluate the effects of a combination of the two policies analyzed above. We therefore assume that the government permanently cuts each tax rate by 2 percentage points, and simultaneously increases its efforts in the compliance monitoring process, which permanently raises the probability $p$ to $11.2 \%$. The results of this experiment are illustrated in the last row of Table 2, and in Fig. 8, where the transitional dynamics due to the combination of policies are compared with those induced by the tax cut alone. We see that the effects of the policy largely resemble those resulting from a general tax cut. The policy stimulates economic activity and improves welfare, although its impact is quantitatively smaller compared with the impact of the tax cut alone. We also find that combining the two policies is extremely effective in discouraging tax evasion, which in the quarter following the policy changes falls by about $25 \%$ and subsequently converges to the new steady state. Again, this pattern mirrors the response of underground production, which in the long run decreases by $16.8 \%$. As a result of this effect, and given the expansion in GDP, such a policy mix induces a significant decrease in the size of the underground economy, which in the steady state falls by $20.4 \%$. Most importantly, we find that mixing the

\footnotetext{
16 This effect is apparent in Fig. 7, which shows that over the whole transition to the new steady state, the regular wage rate is higher than its benchmark counterparts.

17 It is worth pointing out that the predicted welfare costs of this policy are likely to be underestimated. The reason is that in our model assumes that a stronger enforcement process can be implemented by the government without absorbing aggregate resources. In practice, however, intensifying enforcement means employing more tax inspectors, which is costly: it uses labor resources that could have been used for other types of production. Hence, the crowding-out effect of a stronger monitoring process on consumption and investment described above is likely to be larger than the one predicted by our model, and thus also the associated welfare costs. We would like to thanks the Editor for bringing this point to our attention.
} 
two policies raises fiscal revenues both in the steady state (2.52\%), and during the whole transition path. According to these results, for Italy it would therefore be desirable to implement a general tax cut accompanied by stronger monitoring process since, as we have seen, the joint implementation of these two policies would increase welfare and, at the same time, permanently improve its budgetary situation.

\section{Some concluding remarks}

In this paper, we develop and estimate a two-sector DSGE model that explicitly accounts for concealed transactions in the economy. Our goal is twofold: to estimate size and trend of the underground economy and to assess the effects of alternative fiscal policies aim at reducing the underground economy in an economic environment characterized by tax evasion.

We apply our methodology to the Italian economy, using quarterly aggregate data covering the period 1982-2006. The Bayesian estimate of the theoretical model, applying the theory for measurement approach, produces a time series for the underground economy. We find evidence of a steadily upward trend in the size of the underground economy, primarily driven by the persistent increase in taxation that has been observed in Italy since the eighties. As far as fiscal policy is concerned, numerical experiments based on the estimated model show that, at actual tax rates, Italy is on the slippery side of the steady-state Laffer curve, and can improve its budgetary situation by either reducing taxes or strengthening tax enforcement efforts. However, the analysis of transitional dynamics reveals that the optimal strategy for the government would be to undertake a combination of the two policies, as this turns out to be the only fiscal adjustment that can improve welfare and, at the same time, permanently increase fiscal revenues.

To conclude, we wish to stress that our paper presents a new method of estimating the underground economy. The novelty of our approach with respect to those available in the literature lies in its use of a structural model in which the underground economy is an integral part of the economic system. Such a method makes it possible to estimate the unobservable underground economy by exploiting the information provided by the equilibrium conditions of the model. We believe that this methodology is fairly general and can readily be applied to other countries in order to perform a comparative analysis of the causes of the underground economy. Moreover, the theoretical model can be easily modified to assess the implications for the labor market. However, we have left these issues for future research.

\section{Acknowledgments}

We are grateful to our Coordinating Editor, Gianluca Violante, an anonymous Associate Editor, and two anonymous referees for their comments and suggestions, which greatly improved the quality of the paper. We are also grateful to Francesco Busato, Claudio Campanale, Efrem Castelnuovo, Michele Catalano, Iñigo Iturbe-Ormaetxe, Antonio Navas-Ruiz, Paolo Onofri, Climent Quintana-Domeque, Guido Ruta and Francesco Serti, as well as to the participants at presentations held at the University of Bologna, the Fifth Italian Congress of Econometrics and Empirical Economics (Genoa), Third International Conference in memory of Carlo Giannini (Bank of Italy, Rome), Macroeconomic and Policy Implications of the Underground Economy and Tax Evasion (Bocconi University, Milan) for their helpful feedback. We wish to thank Stefano Pisani for kindly sharing his data on fiscal controls with us. We would also like to thank Tommaso Proietti for providing us with the Ox code for disaggregating quarterly time series. Francesco Turino is grateful for the financial support provided by the Spanish Ministerio de Educación y Ciencia and FEDER funds (project SEJ-2007-62656/ECON). All remaining errors are ours.

\section{Appendix A. Graphical results based on posterior estimates}

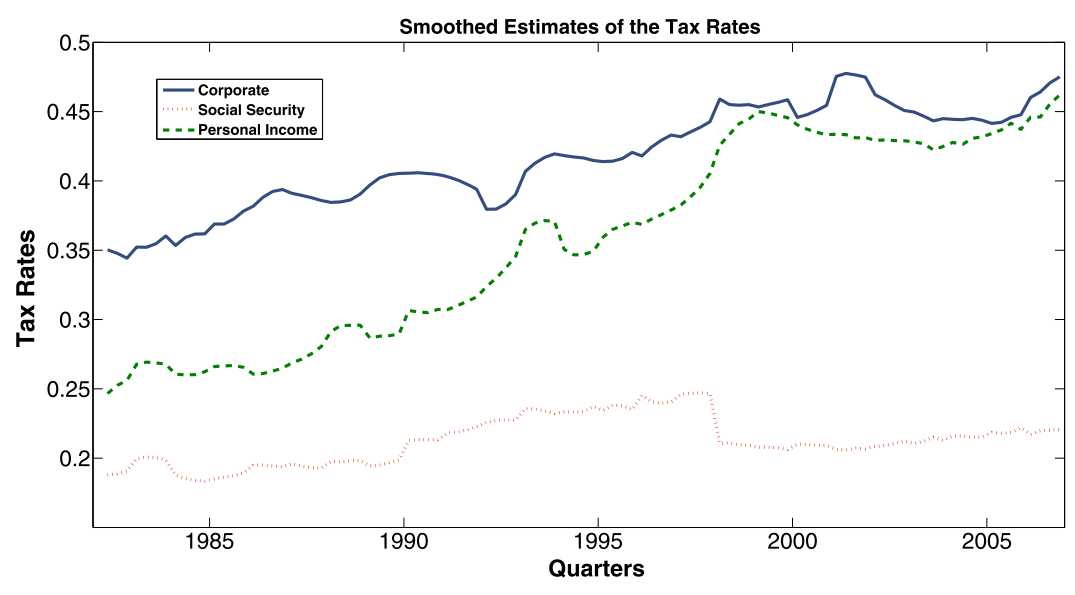

Fig. 4. Smoothed estimate of the tax rates. 

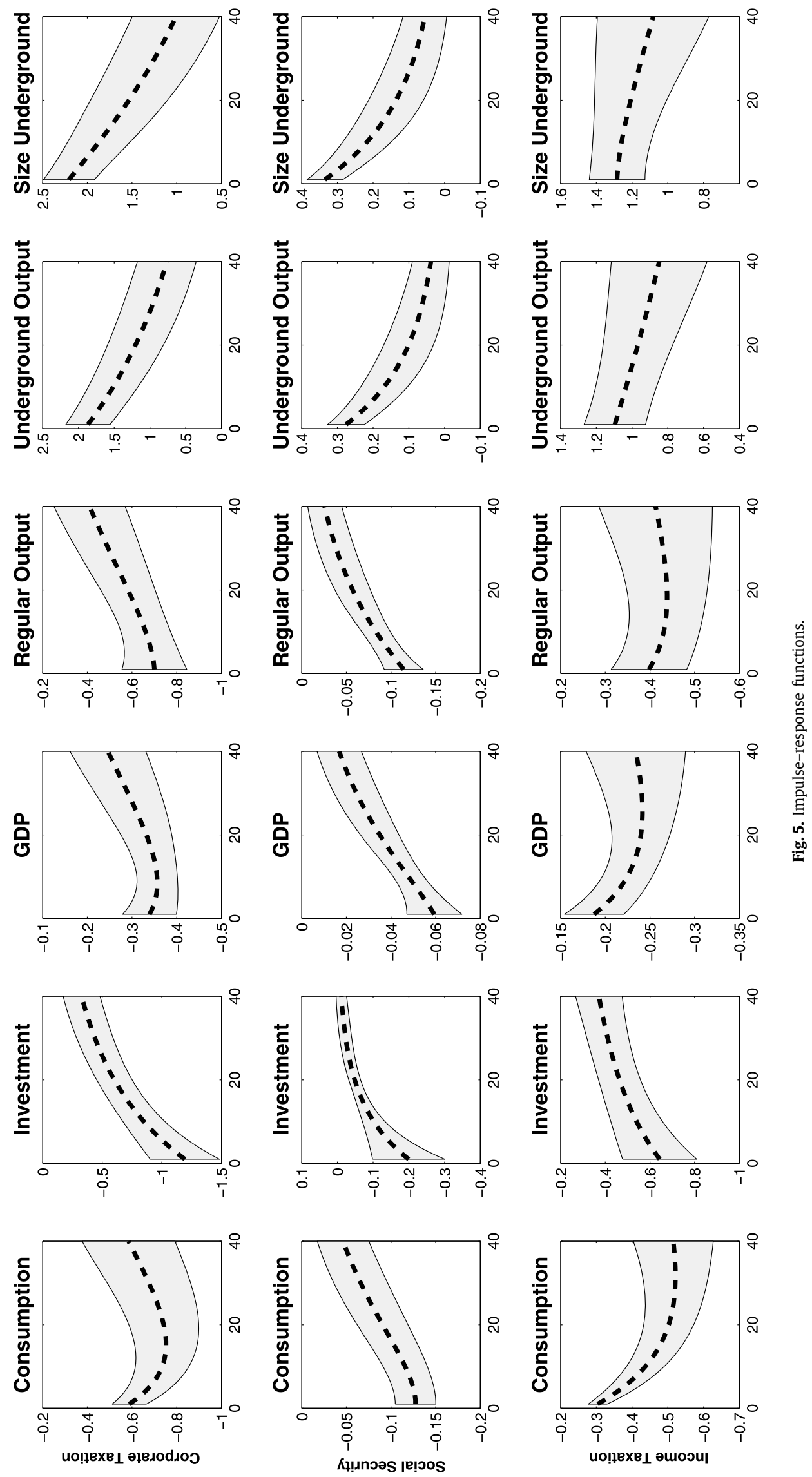

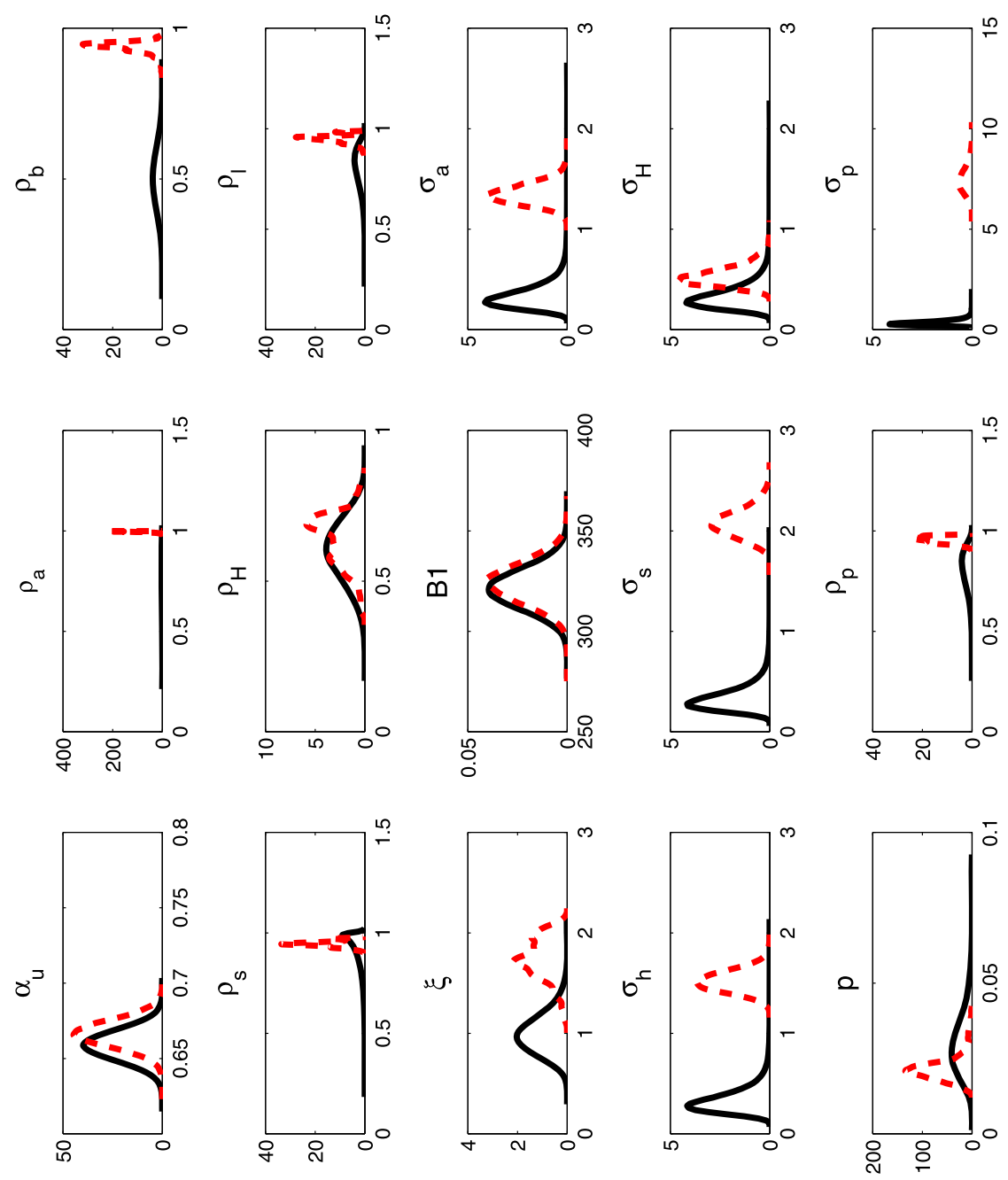

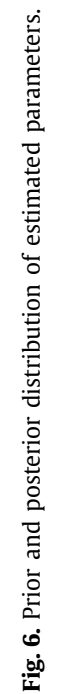
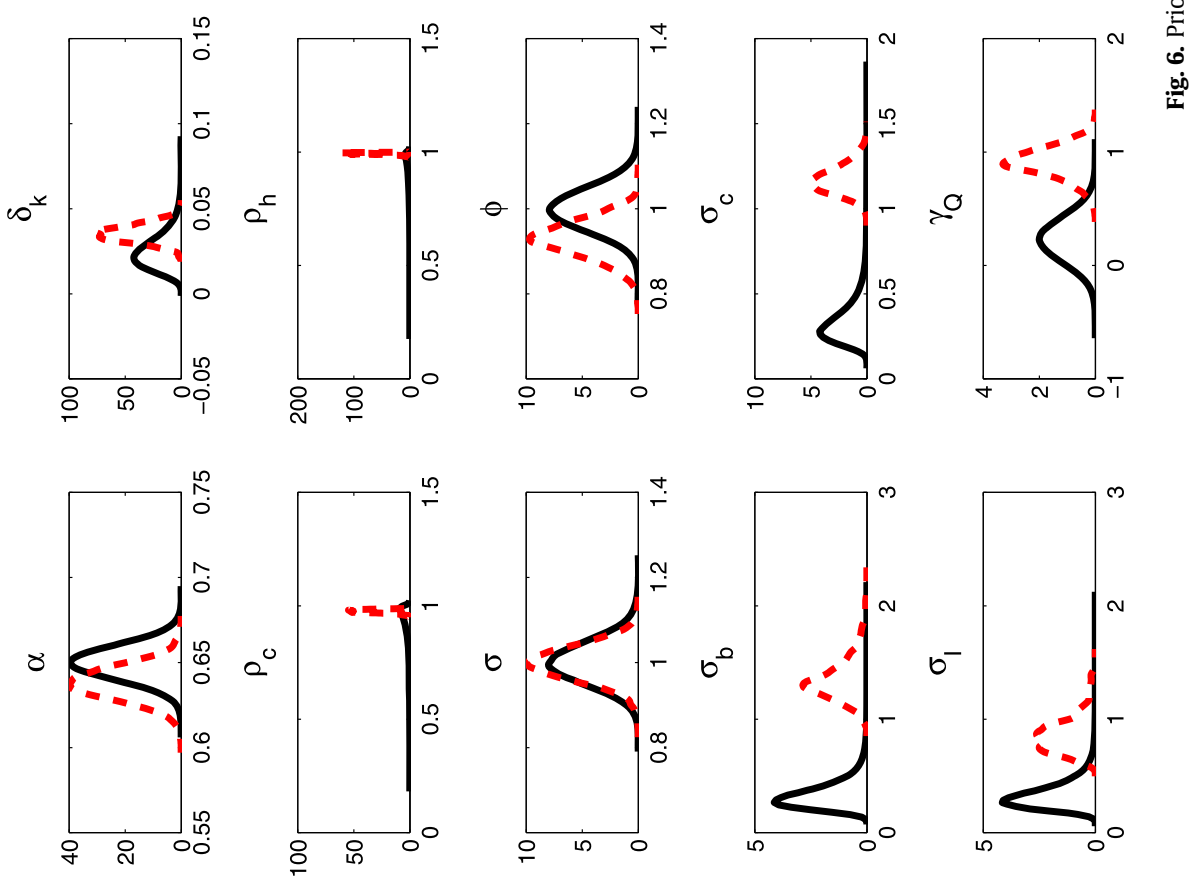

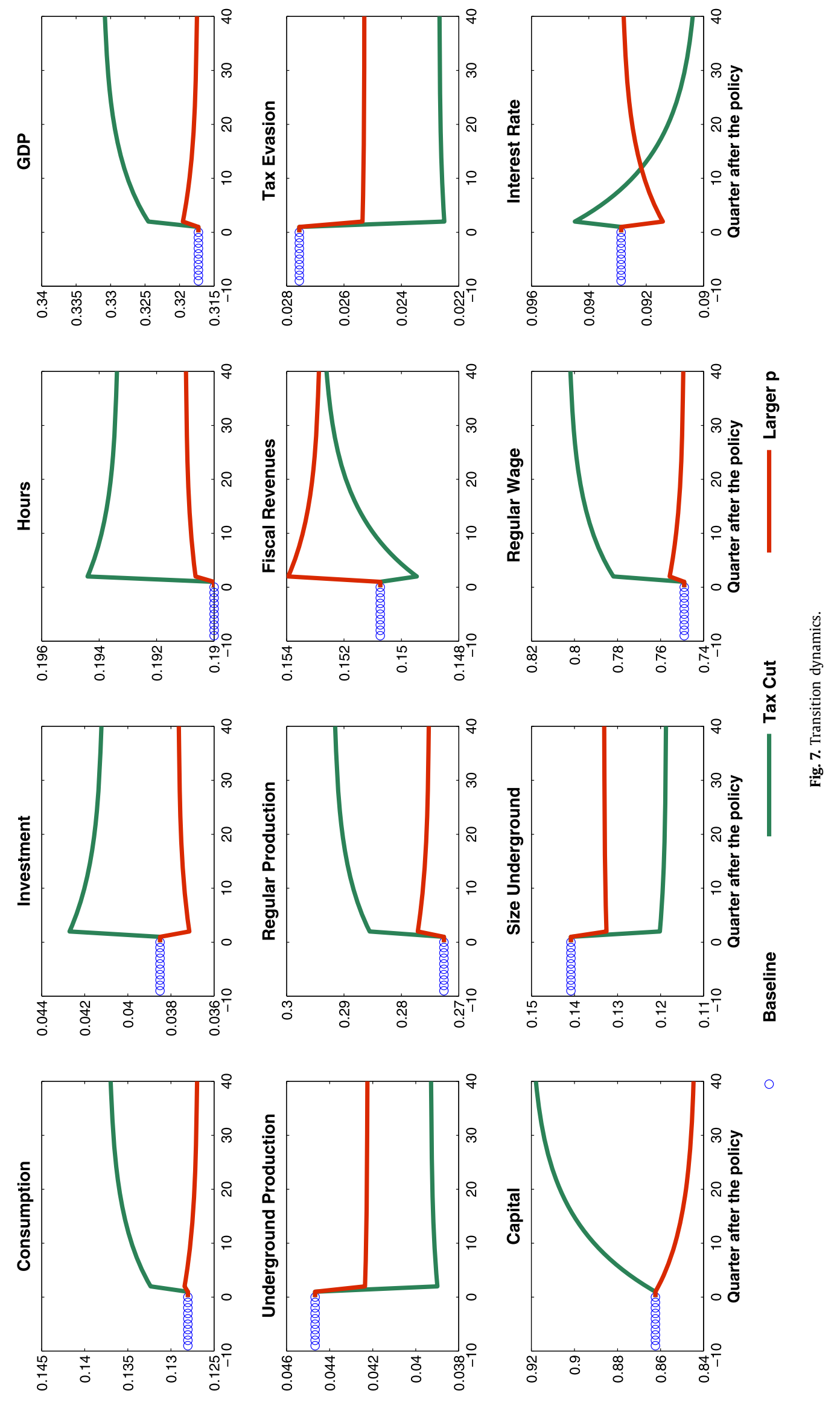

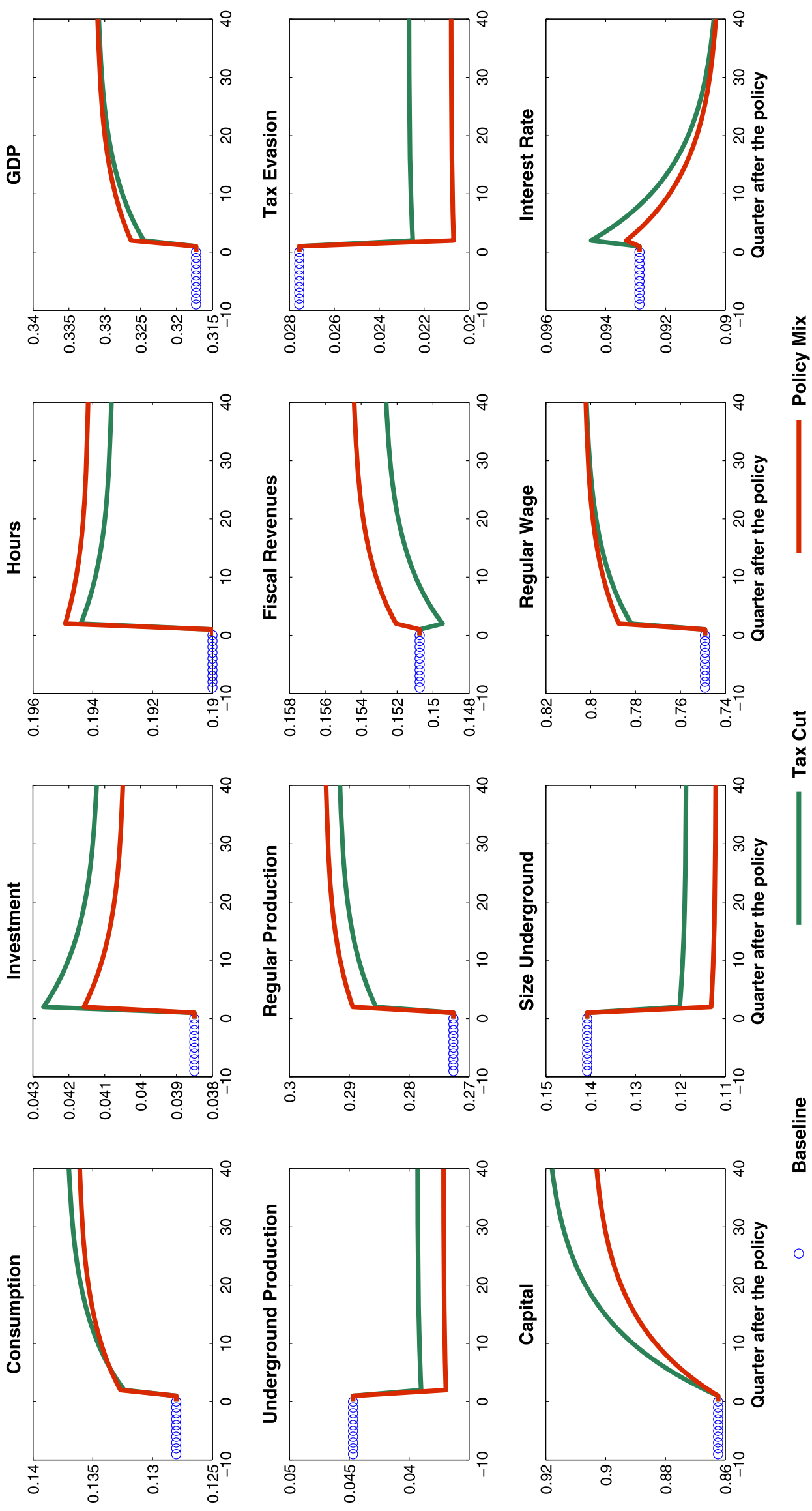


\section{Appendix B. Supplementary material}

Supplementary material related to this article can be found online at http://dx.doi.org/10.1016/j.red.2013.11.001.

\section{References}

Allingham, M.G., Sadmo, A., 1974. Income tax evasion: A theoretical analysis. Journal of Public Economics 3 (2), $201-202$.

Amaral, P.S., Quintin, E., 2006. A competitive model of the informal sector. Journal of Monetary Economics 53 (7), $1541-1553$.

An, S., Schorfheide, F., 2007. Bayesian analysis of DSGE models. Econometric Reviews 26, 113-172.

Antunes, A.R., Cavalcanti, T.V.d.V., 2007. Start up costs, limited enforcement, and the hidden economy. European Economic Review 51 (1), $203-224$.

Basile, R., Chiarini, B., Marzano, E., 2012. Can we rely upon fiscal policy estimates in countries with unreported production of 15 per cent (or more) of GDP?. Working Papers 1. Department of the Treasury, Ministry of the Economy and of Finance.

Busato, F., Chiarini, B., 2004. Market and underground activities in a two-sector dynamic equilibrium model. Economic Theory 23 (4), 831-861.

Busato, F., Chiarini, B., 2012. Steady state Laffer curve with the underground economy. Working Papers 8. Department of the Treasury, Ministry of the Economy and of Finance.

Cagan, P., 1958. The demand for currency relative to total money supply. Journal of Political Economy 66, 303-328.

Canova, F., Sala, L., 2009. Back to square one: Identification issues in DSGE models. Journal of Monetary Economics 56 (4), $431-449$.

Cho, J.-O., Cooley, T.F., 1994. Employment and hours over the business cycle. Journal of Economic Dynamics \& Control 18 (2), $411-432$.

Cho, J.-O., Rogerson, R., 1988. Family labor supply and aggregate fluctuations. Journal of Monetary Economics 21 (2-3), 233-245.

de Jong, P., Shephard, N., 1995. The simulation smoother for time series models. Biometrika 82, 339-350.

de Paula, A., Scheinkman, J.A., 2011. The informal sector: An equilibrium model and some empirical evidence from Brazil. The Review of Income and Wealth 57.

Dell'Anno, R., 2003. Estimating the shadow economy in Italy: a structural equation approach. Tech. rep., Working paper No. 2003-07. Department of Economics, Aarhus University.

Doornik, J., 2001. Ox: An Object-Oriented Matrix Programming Language. Timberlake Consultants Press, London.

Fernandez-Villaverde, J., Rubio-Ramirez, J.F., 2007. Estimating macroeconomic models: A likelihood approach. Review of Economic Studies 74 (4), 1059-1087. Fiorio, C., Santoro, A., 2012. Taxpayer response to an increased probability of audit: some evidence from Italy. Mimeo.

Frey, B., Weck-Hannemann, H., 1984. A hidden economy as an "unobserved" variable. European Economic Review 26, 33-53.

Gallaway, J.H., Bernasek, A., 2002. Gender and informal sector employment in Indonesia. Journal of Economic Issues 36 (2), $313-321$.

Giles, D., 1999. Measuring the hidden economy: implications for econometric modelling. The Economic Journal 109, $370-380$.

Greenwood, J., Hercowitz, Z., Huffman, G.W., 1988. Investment, capacity utilization, and the real business cycle. The American Economic Review 78 (3), $402-417$.

Gutmann, P., 1977. The subterranean economy. Financial Analysts Journal 33, 26-27.

Iacoviello, M., Neri, S., 2010. Housing market spillovers: Evidence from an estimated DSGE model. American Economic Journal: Macroeconomics 2 (2), $125-164$.

Ingram, B.F., Kocherlakota, N.R., Savin, N.E., 1997. Using theory for measurement: An analysis of the cyclical behavior of home production. Journal of Monetary Economics 40 (3), 435-456.

Justiniano, A., Primiceri, G.E., Tambalotti, A., 2010. Investment shocks and business cycles. Journal of Monetary Economics 57 (2), $132-145$.

Koopman, S., Shephard, N., Doornik, J.A., 1999. Statistical algorithms for models in state space using SsfPack 2.2. Econometrics Journal 2, $113-166$.

Leonard, M., 1998. Invisible Work, Invisible Workers: The Informal Economy in Europe and the US. St. Martin's Press, New York.

Lucas, R.E., 1978. On the size distribution of business firms. Bell Journal of Economics 9 (2), 508-523.

Marcelli, E.A., Pastor Jr., M., Joassart, P.M., 1999. Estimating the effects of informal economic activity: Evidence from Los Angeles county. Journal of Economic Issues 33 (3), 579-607.

Mavroeidis, S., Zwols, Y., 2007. LiRE an Ox package for solving linear rational expectations models version 3.0. Tech. rep. Brown University. Working paper. OECD, 2002. Measuring the Non-Observed Economy: A Handbook. Organization for Economic Co-Operation and Development, Paris.

Proietti, T., 2006. Temporal disaggregation by state space methods: Dynamic regression methods revisited. Econometrics Journal 9 , $357-372$.

Schmitt-Grohe, S., Uribe, M., 1997. Balanced-budget rules, distortionary taxes, and aggregate instability. Journal of Political Economy 105 (5), 976-1000.

Schneider, F., 2005. Shadow economies around the world: What do we really know?. European Journal of Political Economy 21, $598-642$.

Schneider, F., Enste, D., 2012. The Shadow Economy: An International Survey, second edition. Cambridge University Press, Cambridge.

Schneider, F., Buehn, A., Montenegro, C.E., 2010. New estimates for the shadow economies all over the world. International Economic Journal 24, 443-461.

Sims, C., 2002. Solving linear rational expectations models. Computational Economics 20, 1-20.

Smets, F., Wouters, R., 2007. Shocks and frictions in us business cycles: A Bayesian DSGE approach. The American Economic Review 97 (3), $586-606$.

Tanzi, V., 1980. The underground economy in the united states: Estimates and implications. Banca Nazionale del Lavoro Quarterly Review $135,427-453$.

Tanzi, V., 1983. The underground economy in the united states: Annual estimates, 1930-80. Tech. rep.

Trabandt, M., Uhlig, H., Sep. 2009. How far are we from the slippery slope? The Laffer curve revisited. NBER working papers, National Bureau of Economic Research, Inc. 